\title{
On The Validity Of The Regression Discontinuity Design For Estimating Electoral Effects: New Evidence From Over 40,000 Close Races
}

\author{
Andrew C. Eggers - London School of Economics \\ Anthony Fowler - University of Chicago \\ Jens Hainmueller - Stanford University \\ Andrew B. Hall - Harvard University \\ James M. Snyder, Jr. - Harvard University and NBER
}

First Version: May 2013

This version: March 2014

\begin{abstract}
The regression discontinuity $(\mathrm{RD})$ design is a valuable tool for identifying electoral effects, but this design is only effective when relevant actors do not have precise control over election results. Several recent papers contend that such precise control is possible in large elections, pointing out that the incumbent party is more likely to win very close elections in the U.S. House of Representatives in recent periods. In this paper, we examine whether similar patterns occur in other electoral settings, including the U.S. House in other time periods, statewide, state legislative, and mayoral races in the U.S., and national or local elections in a variety of other countries. No other case exhibits this pattern. We also cast doubt on suggested explanations for incumbent success in close House races. We conclude that the assumptions behind the RD design are likely to be met in a wide variety of electoral settings and offer a set of best practices for RD researchers going forward.
\end{abstract}

Word Count: 8,593

Forthcoming in American Journal of Political Science.

For generously providing data, the authors thank Alberto Abadie, Melissa Dell, Fernando Ferreira, Alexander Fouirnaies, Ronny Freier, Danny Hidalgo, Yusaku Horiuchi, and Carl Klarner. For helpful comments, we thank Devin Caughey, Justin Grimmer, Gary King, and Jas Sekhon. We especially thank Olle Folke for his collaboration on earlier drafts of this paper as well as his enthusiastic support throughout the project. 
In recent years the regression discontinuity $(\mathrm{RD})$ design has become widely used in political science. In general, RD designs are used to estimate the effect of a treatment that is applied at a threshold value of a continuous variable; in the first application, for example, Thistlethwaite and Campbell (1960) measured the effect of a scholarship by comparing the subsequent performance of students whose test scores were just high enough to win the scholarship to that of students who narrowly fell short. ${ }^{1}$ In political applications, the most common use of RD has been to measure the effect of election results on various political and economic outcomes of interest. $^{2}$ These applications take advantage of the fact that in two-candidate plurality elections the "treatment" - winning the election - is applied to any candidate who surpasses the vote share threshold of 50 percent. ${ }^{3}$ This discontinuous relationship between political support and electoral success is what accounts for the intuitive appeal of the RD design as a strategy for estimating the causal effects of election outcomes: because the treatment depends only on a threshold value of political support, candidates or parties that receive just enough support to win may be fundamentally similar (and thus comparable) to candidates or parties that narrowly lose.

Three recent papers suggest that, despite the intuitive appeal of the RD design, the winners and losers of close elections may not in fact be comparable. Jason Snyder (2005) shows that in U.S. House elections between 1926 and 1992, incumbents won a disproportionate share of very close races. Caughey and Sekhon (2011) investigate this further and show among other things that winners in close U.S. House races raise and spend more campaign money. Grimmer et al. (2012) show that U.S. House candidates from the party in control of state offices, such as the governorship, secretary of state, or a majority in the state house or state senate, hold a systematic advantage in close elections. ${ }^{4}$ Interpreted most narrowly, these studies suggest

\footnotetext{
${ }^{1}$ The data used in this study can be downloaded for replication from the AJPS Data Archive on Dataverse. The Supporting Information (SI) is posted on the AJPS website.

${ }^{2}$ Examples include Lee, Moretti and Butler (2004), DiNardo and Lee (2004), Hainmueller and Kern (2008), Leigh (2008), Pettersson-Lidbom (2008), Broockman (2009), Butler (2009), Dal Bó, Dal Bó and Snyder (2009), Eggers and Hainmueller (2009), Ferreira and Gyourko (2009), Uppal (2009, 2010), Cellini, Ferreira and Rothstein (2010), Gerber and Hopkins (2011), Trounstine (2011), Boas and Hidalgo (2011), Folke and Snyder Jr. (2012), and Gagliarducci and Paserman (2012).

${ }^{3}$ More generally, in any plurality election a candidate's result is a discontinuous function of her vote share, with a threshold that depends on the performance of other candidates.

${ }^{4}$ We are also aware of one other working paper identifying a potential concern with the RD design in close elections. Vogl (2012) finds that black candidates are better at winning close races than their white opponents
} 
that the electoral RD design cannot be applied in a straightforward manner to U.S. House elections, given that the winners and losers of close races for this legislature appear to differ systematically. More broadly, these studies cast doubt on the whole enterprise of using the electoral RD design to learn about politics, given that the manipulation necessary to produce such systematic differences would likely afflict close elections in other electoral settings as well. ${ }^{5}$

In this paper, we consider the validity of electoral RDs from an empirical and theoretical perspective in light of these critiques. We review the assumptions behind the regression discontinuity design as formalized by Lee (2008) and consider their applicability to close elections. We then assess whether the evidence of systematic incumbent advantages in the U.S. House indicates a general problem with the use of RD to measure electoral effects. First, we assess whether similar problems arise in other electoral settings, including every partisan, singlewinner, plurality/majoritarian election setting where data could be collected and assembled. We study elections to the U.S. House in other time periods as well as statewide, state legislative, and mayoral races in the U.S; we also study national and/or local elections in a variety of other countries including the U.K., Canada, Germany, France, Australia, India, Brazil, and Mexico.

We do not find a single other case that exhibits systematic incumbent advantages. We then consider from a theoretical perspective the mechanisms that could produce the type of incumbent advantages that have been detected in the post-World War II U.S. House, concluding that existing explanations are not convincing. This suggests that the unusual success of incumbents in very close House elections might result from chance rather than the ability of incumbent candidates to manipulate outcomes in this context and that evidence of incumbent dominance in close U.S. House elections does not pose a general threat to the validity of RD designs in electoral settings.

We conclude the paper by providing recommendations to future researchers estimating

in mayoral races in the U.S. South (but not elsewhere). However, the statistical evidence is weak since there have been very few close mayoral races in the South between a white and black candidate. In Vogl's sample, there are only 38 such cases (from 18 unique cities) where the margin of victory was less than 20 points.

${ }^{5}$ Substantively, these studies also of course raise the prospect that fraud and other forms of electoral manipulation may be more common in U.S. House races than has been appreciated. We concentrate on methodological implications here. 
electoral effects using RD designs. Consistent with Caughey and Sekhon (2011), we argue that the burden is on empirical researchers to justify their assumptions with theory and data. We advocate a three-step procedure combining theory and data analysis that should guide researchers in assessing the validity of an electoral RD in a particular setting. We pay particular attention to the problem of multiple testing, noting that statistical imbalance is expected to arise by chance from time to time and does not automatically invalidate the underlying assumption of an RD design, and we also point out that the RD design may continue to be the best available estimator even when imbalances are present, relying as it does on more transparent and plausible assumptions than available alternatives.

In short, despite recent concerns we believe that the regression discontinuity design is a fundamentally sound and widely applicable approach to learning about the effect of election results on a variety of political and economic outcomes. Although there are potentially many issues with applying RD to any particular setting, the evidence of incumbent dominance in very close U.S. House elections over the post-WWII period does not appear to uncover any fundamental problem with electoral RD designs.

\section{The Comparability of Winners and Losers of Close Elections}

The intuitive appeal of the RD design in the analysis of elections derives from the idea that candidates who win and lose close elections should be comparable on average. This comparability depends on the assumption that the candidates or parties under consideration do not have complete control over the vote share they receive. If this were not the case - for example, if better-resourced candidates could examine their opponent's final vote total and then decide whether to increase their own - then the winners and losers of close elections may well differ systematically. Lee (2008) formalizes this logic, showing that a comparison of narrow winners and losers identifies the average treatment effect of winning at the threshold as long as there is an exogenous random chance component to candidates' vote shares that has a continuous density (also see Hahn, Todd and Van der Klaauw (2001)).

A priori, the fundamental continuity assumption that implies that candidates do not perfectly control the electoral outcome seems likely to be met, not just because the weather or 
far-off current events can influence outcomes (a common justification offered in electoral RD studies), but also because every close election involves (at least) two candidates; the fact that no candidate can control the campaign activities of her opponent would seem to be a strong indication that she cannot perfectly control her own vote share. Nevertheless, in principle it is of course possible that certain types of candidates could have a degree of precise control over electoral outcomes that would render the electoral RD design invalid. For example, if incumbent candidates had a systematic ability to convert narrow losses to narrow victories through some combination of legal challenges, electoral fraud, and heroic campaign feats, then close winners and losers would no longer be comparable and the RD design would no longer identify the effect of the electoral outcome.

As noted above, recent evidence suggests that winners and losers are not in fact comparable in close elections for the U.S. House of Representatives. Winners of close elections appear to be disproportionately incumbents (Snyder 2005); they also appear to be disproportionately aligned with the locally-dominant party (Grimmer et al. 2012) and, among other things, have more experience and money (Caughey and Sekhon 2011). It is easy to see why such candidates would in general be more electorally successful, but it is less clear why they would disproportionally win what should be essentially coin flips, according to the theory laid out in Lee (2008).

Figure 1 offers one view of the problem in the U.S. House of Representatives for the period from 1946 to 2010. For each 0.5 point bin of Democratic vote margin (for example, all elections where the Democrat margin of victory was between 1.5 and 2 percentage points), we plot the proportion of cases in which a Democrat won the district in the previous election. As expected, there is a smooth, positive relationship between the Democratic margin of victory and the proportion of cases in which a Democrat was an incumbent. However, if we look at the bins immediately on either side of 0 , we see a strange phenomenon. In the 59 total cases in which the Democrat won by less than half a percentage point (i.e. the first bin to the right of the threshold which is equivalent to Democratic vote percentages between 50 and 50.25), a Democrat previously won the seat almost 60 percent of the time; in the 54 total cases in which the Democrat lost by less than half a percentage point (i.e. the first bin to the left 
of the threshold which is equivalent to Democratic vote percentages betwee 49.75 and 50), a Democrat previously won the seat only 25 percent of the time. Within this sample of extremely close elections, we would expect the incumbent party to lose the seat just as often as they win, but it appears to win a disproportionate share of close races. This highlights the exception first identified by Snyder (2005) and pursued further by Caughey and Sekhon (2011).

What accounts for the disproportionate success of the incumbent party in close U.S. House races? Snyder (2005) interprets it as evidence of corrupt electoral manipulation, suggesting that the complexity of the process of collecting and tabulating votes in close elections leaves opportunities for incumbent candidates to somehow tamper with the results of close elections. Grimmer et al. (2012) expand on these ideas in analysis of a longer period of U.S. House races (1880-2008), showing that (particularly in the earlier period) candidates from the party that controlled local and state offices had a similarly substantial advantage; they suggest that part of the reason why "structurally advantaged candidates" disproportionately win close elections is that they are more successful in post-election legal battles. While conceding that a convincing explanation for this sorting remains elusive, Caughey and Sekhon (2011) point to the ability of well-organized campaigns to obtain precise information about likely outcomes and to take extraordinary measures to secure victory in very close races.

We return to these explanations for sorting in U.S. House elections below. For now we note that the evidence of sorting in close U.S. House elections appears to cast doubt on the validity of RD as a strategy for measuring electoral effects not just in the U.S. House but in a much broader class of electoral contexts. Although close U.S. House races are different in some respects (e.g. more money raised and spent, more polling conducted) from close races in most other settings, there would seem to be at least as much scope for precise manipulation of outcomes in many other contexts. In legislative elections in many developing democracies, for example, electoral fraud is more common than in closely-monitored U.S. House contests (Lehoucq 2003; Simpser 2013). Polling technology is less widely used in most settings where researchers are interested in using $\mathrm{RD}$ to measure electoral effects, but in many of these settings the electorate is much smaller, such that candidates arguably have similarly precise information about likely outcomes. The existing evidence of systematic incumbent advantages in close U.S. 
House elections may therefore be thought to pose a quite general threat to the validity of RDbased electoral studies.

In the next section we begin assessing the nature of this threat by examining evidence of incumbent advantage in other electoral settings. This evidence helps inform our subsequent theoretical analysis, which asks what mechanisms could account for the patterns of incumbent advantage we uncover.

\section{Why Focus on INCUMBENCY?}

In principle, in electoral $\mathrm{RD}$ designs as in other $\mathrm{RD}$ designs one could check for differences between narrow winners and losers in as many characteristics as one can measure. In assessing the validity of electoral RD designs across various political settings, we focus on the role of incumbency: does the incumbent party disproportionately win close elections? We focus on incumbency for three reasons, which we can characterize roughly as an empirical reason, a statistical reason, and a theoretical reason.

The empirical reason for focusing on incumbency is that although existing studies have pointed out differences between winners and losers in a variety of characteristics, all of these differences can be viewed as proxies for incumbency. Caughey and Sekhon (2011) test for imbalances in the largest set of background covariates, showing that in addition to the incumbent party, candidates who received a higher vote share in the previous election, spent more money, or were predicted to win (among other differences), were more likely to win very close elections. ${ }^{6}$ As shown by Table 1, however, the covariates Caughey and Sekhon (2011) study are so highly correlated with the party of the incumbent that after controlling for the party of the incumbent the evidence of imbalance in the other covariates disappears. In the leftmost column of that table we report the full list of covariates for which Caughey and Sekhon (2011) find substantial imbalance. To document imbalance, they restrict attention to close elections

\footnotetext{
${ }^{6}$ Caughey and Sekhon (2011) report that barely winners received more campaign contributions and spent significantly more money than barely losers. In testing for these imbalances, they are careful to use a measure of contributions that removes those made after election day. In our own analysis (available from the authors upon request), we confirm that these post-election contributions flow largely to the incumbent, suggesting that post-election financial activity could exacerbate imbalances. This is important because, unlike the contribution data, it is impossible to separate the expenditure data into pre- and post-election. Thus the larger imbalance found on expenditures is likely to be driven, at least in part, by post-election activity.
} 
(defined as those with a margin of less than half a percentage point) and compute the mean difference for each covariate between districts in which the Democrat wins and districts where the Democrat loses. The middle column (labeled "Original Specification") reports the p-value corresponding to their test of the null hypothesis that this expected difference is zero. ${ }^{7}$ In the rightmost column we report p-values from another analysis that differs only in that incumbency (i.e. "Democratic Win") is added as a control. ${ }^{8}$ The fact that none of these p-values is below .1 indicates the high degree of collinearity between incumbency and each of these covariates. This suggests that focusing on incumbency may be sufficient for detecting similar patterns in other electoral settings: imbalance on incumbency produces imbalance on these other variables as well, and the purported imbalances on these other variables go away once we account for incumbency. ${ }^{9}$

The statistical reason for focusing on incumbency rather than searching for imbalances in a larger set of variables is a concern about multiple testing. If we test for differences between winners and losers in a large enough set of variables we will eventually find it by chance even if the assumptions underlying RD are in fact met. Future studies may seek to test other variables while applying corrections for multiple testing, but here we focus on the single variable that is purported to be the most problematic and conduct the same battery of tests across many different electoral settings.

The theoretical reason for focusing on incumbency is that it is a factor that has been shown to confer electoral benefits in a variety of electoral settings around the world (Katz and King 1999; Hainmueller and Kern 2008; Horiuchi and Leigh 2009; Ariga 2010; Kendall and Rekkas 2012). ${ }^{10}$ Of course, in particular settings other factors may confer systematic electoral advantages: in some local elections, for example, candidates may benefit from belonging to the party controlling a higher-level office; in other settings being part of a political dynasty

\footnotetext{
${ }^{7}$ The p-values reported differ slightly from the ones depicted in Figure 2 of Caughey and Sekhon (2011) because we restrict attention to the subset of districts for which the party of the incumbent is defined, and also because we employ OLS while they employ a Wilcoxon rank sum test.

${ }^{8} \mathrm{As}$ expected, we obtain the same results from a separate analysis where we regress each covariate on lagged incumbency, calculate the residuals, and test for balance on the residuals.

${ }^{9} \mathrm{Put}$ another way, even though we observe imbalances on many covariates, they all tap into a single underlying factor (incumbency) and so are not independent pieces of information.

${ }^{10}$ Though see also Linden (2004); Uppal (2009); Aidt, Golden and Tiwari (2011); Klašnja and Titiunik (2013) for evidence of incumbency disadvantage in India and Brazil.
} 
may be particularly politically advantageous (e.g., Dal Bó, Dal Bó and Snyder 2009; Querubin 2011). Unlike these factors, incumbency status is well-defined and easily measured in all singleseat electoral systems and is thus a natural attribute to focus on as we look for systematic differences between winners and losers of close elections.

\section{Do Incumbents Disproportionately Win Close Elections?}

We analyze data for every partisan, single-winner, plurality/majoritarian electoral setting where data could be collected and assembled. This sample includes national legislative elections in every country that has held competitive, plurality elections continuously since at least 1960 and local elections in several politically significant settings. In total, we analyze 20 electoral settings in 10 different countries. The data sets are listed in Table 2; in the Supporting Information (SI) Appendix A we provide the source of each data set and details on how we handled issues such as redistricting and multi-party competition. ${ }^{11}$ We follow Caughey and Sekhon (2011) in choosing a reference party for each setting (e.g. the Democrats in U.S. data sets; the Conservatives in the U.K. data sets) and calculating vote margins and incumbency status with respect to that party of interest. The vote margin for the reference party is the difference in vote share between the party of interest and the highest finisher among the other parties. Table 2 reports the number of races in each data set (as well as in the pooled data set) where the margin of victory was less than 10, 2, and 1 percentage points. For example, a bandwidth of 1 includes all elections where the reference party won or lost by a margin of 1 point or less. In a case with only two parties, this would include all cases where the reference party won between 49.5 and 50.5 percent of the vote.

Table 3 assesses whether incumbent parties disproportionately win close elections in a variety of settings. Our basic strategy is to test for an "effect" of winning an election at time $t$ on incumbency status in time $t-1$. We carry out this placebo analysis using three common RD approaches. The "difference-in-means" analysis compares the mean values of the placebo outcome (an indicator for whether the reference party won the previous election) in narrow

\footnotetext{
${ }^{11}$ In all settings we omit cases where the difference in vote share between the first and third place party is less than 5 percentage points; this is to avoid complexities emerging from close races involving more than two parties.
} 
windows above and below the electoral threshold. ${ }^{12}$ "Local linear" analysis similarly tests for a jump in incumbency status at the threshold where the party of interest's vote margin changes from negative to positive, but it does so by fitting linear regressions on each side of the electoral threshold to account for a potential slope of the regression functions in the window around the threshold. "Polynomial" does the same thing but with a third-order polynomial regression. For each type of analysis, we summarize the results by reporting the p-value on the test for a jump at the threshold, using italics to signal that the placebo treatment effect is negative, i.e. that incumbents appear to do worse. In the SI Appendix B, we present these results graphically and for more specifications. Specifically, in Figures B2-B5 we present the results from the local linear specification for all possible bandwidths between 0.5 and 5 . These graphs also present the point estimates for readers interested in interpreting the substantive size of the point estimates directly and show that the results are robust across many specifications.

As expected, our tests uncover the imbalance in the U.S. House in the post-World War II period (row 3). Previous papers have focused on the "difference-in-means" specification, and we replicate this result for other RD specifications as well. However, for the U.S. House in the previous period as well as for the U.S. House in the entire period since 1880, we fail to find evidence of incumbent advantages in any specification at the .05 level. Turning to the other U.S. contexts (statewide offices since 1946, state legislatures since 1990, and mayors since 1947), we find no evidence of an advantage for the incumbent party in any specification. This finding is particularly interesting given that existing explanations for incumbents' disproportionate success in the postwar U.S. House would seem to apply at least as strongly to these other contexts. Outside the U.S., we similarly fail to find any evidence of an advantage to incumbent party candidates. Out of 96 tests shown for non-U.S. data, we do not find a single p-value

\footnotetext{
${ }^{12}$ The analysis with a bandwidth of 0.5 is equivalent to a test for a difference in the binned means on either side of the threshold in Figure 1. In the RD literature, this is sometimes called a "naive" specification. Despite the benefit of simplicity and transparency, it could produce biased estimates because the potential outcomes are likely correlated with the running variable, even in a small window. For this reason, this specification is only recommended for very small bandwidths where the bias is likely to be negligible. In this particular setting, this bias is likely to lead us to over-estimate the success of the incumbent party in close elections because party performance is positively correlated over time. See Imbens and Lemieux (2008: p.624) for a formal discussion of the bias of the difference-in-means estimator in the RD context. They advocate against the difference in means estimator in the RD context because it is likely that the bias is "relatively high." Table 3 below shows an example of this where in our pooled sample of all close races, the difference-in-means estimator is biased even within a bandwidth of 1 percentage points because it ignores the positive slope within the bin.
} 
below .05. When we pool all of the data into a single data set (bottom row of the table), we similarly find no evidence of incumbent advantages. The one case where the p-value is below .05 is the "difference-in-means" analysis with a bandwidth of 1 , but a closer investigation of this reveals that the difference-in-means estimate is highly biased upwards, since it ignores the strong positive slope within the bandwidth (see Figure B1 in the Appendix which plots the relationship between lagged incumbency and the margin of victory for these close races and shows that even within a 1 percentage point bandwidth, the difference-in-means estimator provides a poor approximation to the limits from below and above of the regression functions towards the threshold). Given this bias, we do not view this estimate as convincing evidence of imbalance. ${ }^{13}$

Figure 2 provides a graphical summary of the results in Table 3 . In the left panel we plot the histogram of the t-statistics of the tests in the first column of Table 3 - difference-inmeans estimates of the difference in lagged victory rate between close winners and losers for a bandwidth of 0.5. The t-statistics are evenly distributed around 0 except for a single outlier above 3: the U.S. House in the post-World War II period. In the right panel, we include all of the (non-pooled) tests from Table 3. Again the distribution appears to be roughly unimodal about 0, except for a right tail; every one of the t-statistics greater than 1.96 comes from the U.S. House in the post-World War II period. We present these results graphically and for many more specifications in the SI Appendix B (Figures A2 and A4)

As noted above, our placebo tests focus on (lagged) incumbency because our analysis in Table 1 suggests that incumbency accounts for most of the imbalances reported in existing studies for the U.S. House. It is good practice however to check for balance in the lagged running variable (Imbens and Lemieux 2008), i.e. the vote margin in the previous race. Table 4 reports results of the same tests using the same format as Table 3, where the outcome is the lagged vote margin rather than lagged incumbency status. The difference-in-means analysis shows imbalance in the U.S. House only at the 1 point bandwidth for the post-World War II period; in no setting is there consistent evidence of imbalance. Again, we present these results graphically and for many more specifications in the SI Appendix B (Figures A3 and

\footnotetext{
${ }^{13}$ In fact, if party performance is correlated over time, a difference-in-means test should yield a significant result at any bandwidth given sufficient data, even if incumbents have no special advantages in close elections.
} 
A5). Histograms of test statistics are displayed in Figure 3 and indicate a similar pattern to the one in Figure 2: t-statistics appear to be drawn from a unimodal density centered about 0 .

In Table 5 we report the results of additional analysis based on the density test suggested by McCrary (2008). In these tests, we assess whether the density of incumbent-party candidates' vote share is smooth near the electoral threshold. We first separate each data set according to whether the party of interest previously won the seat or not ("Incumbent" vs. "Non Incumb") and carry out the McCrary test separately on each series, restricting attention to cases where the margin of victory was within 10 percentage points. If incumbents disproportionately win close elections, we would expect a break in the density of the vote margin at 0 - a jump up for the sample of elections in which the party of interest held the seat and a drop down for the sample of elections in which the party of interest did not hold the seat. We do not generally find this pattern; even the results for the U.S. House in the post-World War II period are only borderline significant for the "Incumbent" series. We then recombine the two subsets while flipping the sign of the vote margin for the cases in which the party of interest was not the incumbent; for this combined data set, we would expect a bulge in the density where the adjusted margin is slightly above 0 , indicating that the party of interest is likely to narrowly lose when it previously lost and likely to narrowly win when it previously won. As indicated by Table 5, we cannot reject the null of no density jump for any setting except the U.S. House after 1946 .

\section{What Mechanisms Could Lead to Imbalance in Electoral RD Designs?}

The analysis in the previous section indicates that the apparent dominance of incumbent-party candidates is limited to the U.S. House in the post-World War II period. What does this mean for the use of electoral RD designs? The most optimistic conclusion is that the disproportionate rate of success among incumbents in close House elections is the result of statistical chance, which would indicate no fundamental problem for electoral RD analysis (although researchers applying an RD to the U.S. House need to take special care). Other interpretations are possible, however. For example, one could conclude that some class of candidates is able to 
precisely control electoral outcomes in many settings, but that this advantaged class varies across settings. If so, we might find imbalance in incumbency status only in the U.S. House (and only in the post-WWII period), even though the assumptions behind the electoral RD design are violated more widely.

In order to clarify the significance of the imbalances in the postwar U.S. House, we briefly discuss the theoretical mechanisms through which incumbents (or other structurally-advantaged candidates) could exert fine control over the outcome of close elections. Along the way, we assess the plausibility of those mechanisms in the case of the U.S. House. In the end, we conclude that none of the current explanations for the imbalance observed in the U.S. House are satisfying. This suggests that this imbalance is likely the result of chance. Nonetheless, researchers must think carefully about these potential mechanisms, whether they are present in a particular electoral setting, and whether they might bias estimates arising from future RD designs. We also use this discussion to motivate our next section which provides a set of best practices - both theoretical and empirical - that future researchers should employ when implementing RD designs in electoral settings.

Explanations for systematic advantages of incumbents (or other advantaged candidates) in close elections can be crudely divided into two categories: those that focus on pre-election behavior, like the campaign efforts that Caughey and Sekhon (2011) discuss, and those that focus on post-election behavior, including the processing of ballots and the recount process. We consider each type of explanation in turn.

There are several theoretical requirements for any pre-election explanation for imbalance. For example, advantaged candidates must have access to additional (but costly) resources that they only employ when necessary, they would have to obtain extremely precise information about their expected vote share, and the opposing campaign must lack the ability or willingness to do these same things. Here, we focus on the most salient of these requirements: information.

Recall that the imbalance observed in the U.S. House is present for only a tiny window around the electoral threshold, where the Democratic win margin was less than 0.5 percentage points, i.e., those elections where the Democratic two-party vote percentage is between 49.75 and 50.25. If strategic campaigning or other pre-election behaviors explain this imbalance, 
then incumbent behavior must vary significantly across small changes in the expected election result. Specifically, their behavior would have to be systematically different in scenarios where they would expect vote percentages between 49.75 and 50, compared to other scenarios where they would expect vote percentages in the bins immediately outside of this range. For example, incumbents would behave differently if they expect to receive 49.9 percent of the two-party vote as opposed to 49.7 or 50.1 percent. Perhaps at 49.9, incumbents exert extra effort in an attempt to win, but at 49.7, they know the cause is lost so they do not bother, and at 50.1, they rest assured of victory and similarly do not bother exerting extra effort. Of course, this explanation assumes that incumbents can reasonably distinguish between situations where they expect to receive 49.7, 49.9, and 50.1 percent of the vote. In the SI Appendix C, we provide a theoretical model of campaign effort and show that incumbent campaigns would have to predict their vote shares within approximately one-quarter of one percentage point (at most), on average, in order for pre-election behavior to explain the pattern of imbalance that we observe in the U.S. House.

The realities of political polling and congressional campaigns cast serious doubt on the ability of candidates to obtain such precise expectations. Enos and Hersh (2013) provide evidence on the precision of campaign expectations by surveying Democratic candidates and campaign operatives in the run-up to the 2012 general election. On average, campaign workers mis-predict their vote share by 8 percentage points, and this lack of precision does not vary meaningfully across the status of the campaign worker (candidates and high-level managers are no better than volunteers and lower-level workers), the competitiveness of the race, the time until the election, or incumbent vs. challenger campaigns. For the 5 "toss-up" U.S. House races where Enos and Hersh (2013) surveyed the incumbent campaign, the operatives mispredicted the election result by 10 percentage points, on average. Statistical models reveal similar levels of uncertainty about the outcomes of close elections. Klarner (2008) generates race-by-race predictions for the two-party vote share in every contested House election in 2008. On average, for contested races, these predictions miss the actual election result by 4.3 percentage points, and the average error exceeds 6 percentage points for the most competitive races. Likewise, the final poll or even the average of many late polls in a close U.S. House 
race in 2012, on average, missed the actual election result by about 2 percentage points. ${ }^{14}$ With this information available, then, congressional candidates can hardly tell the difference between situations where they are likely to lose narrowly and those where they are likely to win narrowly. In fact, because election outcomes are so uncertain, modern campaign managers and consultants often aim for 52 percent of the two-party vote. ${ }^{15}$ We do not know how they decided upon this magic number, but the fact that these campaigns do not target the actual threshold suggests that it is unlikley that campaign activity can explain the precise imbalance.

Post-election explanations for imbalance - revolving around court cases, recounts, postelection fraud, etc. - are theoretically more plausible. In these cases, candidates might know exactly when to exert costly effort, because the initial vote count is public. Whether or not incumbent candidates (or some other class of candidates) can disproportionately win these battles then depends on the specifics of the particular setting. In the case of the U.S. House, Caughey and Sekhon (2011) rule out these explanations after finding that while recounts occur frequently in close races, they rarely reverse the initial result. This is consistent with the idea that incumbent-party candidates and challengers both bring substantial resources to election contests and thus incumbents cannot dominate at the recount stage. ${ }^{16}$ Other postelection mechanisms would include more flagrantly illegal behavior, such as altering precinctlevel vote tallies after all of the results have been counted. For such a mechanism to account for incumbent dominance in very close U.S. House races, electoral manipulation would have to be widespread, and this type of outright fraud is thought to be rare in this setting and time period (Lehoucq 2003). Moreover, we lack an explanation for why such behavior would be present in postwar House elections but absent not in the prewar House and in postwar

\footnotetext{
${ }^{14}$ We conducted this analysis ourselves by collecting all of the polls available through Real Clear Politics.

${ }^{15}$ This was relayed to us in private correspondence with a campaign consultant.

${ }^{16}$ However, all of the 4 reversals identified and discussed by Caughey and Sekhon (2011) benefited the incumbent party, so recounts may explain some of the observed imbalance. If future work demonstrates that the imbalance in the House is primarily explained by recounts and court cases, there is a workable solution for applied researchers. If the initial vote tally is well-behaved but incumbents disproportionately prevail in recounts, then one can employ a "fuzzy" RD design in which the initial vote tally provides an instrument for the final election result. Note that this requires the usual fuzzy RD assumptions, including monotonicity and excludability (see for example Hahn, Todd and Van der Klaauw (2001)). The fuzzy RD also changes the estimand to the local average treatment effect for compliers, but in practice this estimand will be very close to the one from the sharp RD if recounts rarely reverse the initial vote result and therefore the rate of compliance is very high. We should also point out that data on the initial tallies may be difficult to collect in many cases.
} 
elections for state legislatures and statewide offices.

In sum, we find existing post-election and pre-election explanations of observed imbalances in close U.S. House races to be fairly implausible. Outside of structural advantages to incumbents (or some other class of candidates) in manipulating electoral tallies after the election or in winning legal challenges, there exists no convincing theoretical reason to expect close winners and losers of a large election to differ systematically. The implausibility of the mechanisms that have been suggested to explain imbalance in the postwar U.S. House suggests that the success of incumbent-party candidates in very close elections most likely reflects statistical chance. To be sure, if we look at close elections in the post U.S. House in isolation, we observe a degree of incumbent-party success that appears unlikely to have arisen randomly. ${ }^{17}$ However, given a large number of electoral settings it is likely that this degree of imbalance would emerge in one of them simply by chance. The analysis in this paper suggests that the postwar U.S. House may be that exceptional setting in which imbalance arose by chance. ${ }^{18}$ Of course, this does not preclude the possibility that future work might uncover a more compelling explanation for imbalance in the U.S. House which could lead us to revise this conclusion.

\section{RECOMMEndATIONS FOR Future ReseARCHERS}

In examining the observed imbalance in the U.S. House, as well as in presenting our tests for other electoral offices, we have touched upon the techniques that we believe researchers should employ when validating the RD design in applied settings. The fact that we fail to find problems in numerous electoral settings does not excuse researchers from defending the identification assumptions of their empirical strategies with both theory and data. The burden of proof is on the researcher to justify their assumptions and subject them to rigorous testing. A key advantage of the RD design is that it lends itself to these numerous transparent tests that follow directly from the identification assumptions. In this section, we propose a set of best practices for future researchers. We do not focus on the technical details of the RD design,

\footnotetext{
${ }^{17}$ We cannot say with precision how unlikely this is. With some specifications, the imbalance appears to be extremely unlikely (e.g., $p<.001$ ), but for other specifications, the imbalance is only moderately unlikely (e.g., $p=.07)$. For obvious reasons, we should not focus only on the specification with the lowest $\mathrm{p}$-value.

${ }^{18}$ For example, across 20 independent settings under the null hypothesis, there is a 64 percent chance of obtaining at least one p-value below .05 and an 18 percent chance of obtaining at least one p-value below .01 .
} 
which have already been clearly laid out in, for example, Hahn, Todd and Van der Klaauw (2001), Lee (2008), and Imbens and Lemieux (2008).

To ensure that RD results are both valid and robust, we propose a three-step process. Researchers employing the RD should:

1. Consider theoretical mechanisms that could produce sorting around the discontinuity.

2. Evaluate balance on pre-treatment covariates and especially on the lagged outcome variable, focusing on the presence or absence of substantively large imbalances in characteristics that might be related to the mechanisms that could produce sorting. These tests should employ the same specifications as those employed to estimate the effects of interest, and these specifications should account for the potential relationship between the running variable and the outcome variable.

3. Present estimates at a large number of alternative bandwidths and specifications.

We now discuss these three steps in detail.

\section{Evaluating the RD Assumption Theoretically}

While the RD design is an extremely valuable tool for estimating electoral effects, it is not a panacea. The assumptions of the design are often weaker than those of other designs, but they are not guaranteed to hold. For example, if an electorate is small enough that relevant actors could closely predict or manipulate the vote tally, then the RD assumptions would be invalid. For this reason, the RD design should probably not be used to study the effects of judicial or legislative decisions, where strategic voting, endogenous agendas, or bargaining could lead to systematic differences between successful and unsuccessful motions. As a case in point, McCrary (2008) demonstrates that roll call votes in the U.S. House exhibit sorting around the majority threshold indicating that such votes do not generate a quasi-random assignment of policy decisions. Similarly, in an electoral setting where all close elections were ultimately decided in courtrooms which often reversed the initial counting of ballots, one could only assume that election winners and losers were comparable if one were willing to assume that the legal process were not systematically biased toward one type of candidate. For these reasons, 
a researcher must first provide theoretical justification for their design before examining the data. In any new electoral setting, the researcher should ask the following questions: Are the assumptions of the RD design that potential outcomes are smooth at the electoral threshold defensible a priori? Are there substantive features of this electoral setting that could easily lead the bare winners to be systematically different from the bare losers?

\section{Validating the RD Assumption Empirically}

Having considered possible threats to the validity of the RD design theoretically, researchers should then test their assumptions to the extent possible. At a minimum, they should conduct tests for placebo effects of the treatment on the lagged outcome variable when possible. We also highly recommend that researchers show additional placebo tests for the lagged running variable, lagged treatment variable, and other pre-treatment covariates if available. These placebo tests should mimic, as closely as possible, the specifications used to estimate the primary quantities of interest. We discuss the choice of specifications below. Additionally, graphs and or formal tests for sorting based on McCrary (2008) would further bolster readers' confidence in the underlying assumptions and results (see also Imbens and Lemieux (2008) and Lee and Lemieux (2010) for checklists of tests).

In performing these placebo tests, researchers and consumers should keep in mind the multiple testing problem. Testing for imbalance on many variables makes it likely that some tests will be statistically significant by random chance. Imbalance should be therefore assessed based on the substantive size of the imbalance, and not only on the statistical significance of the balance test. For example, in our analyses, our failure to reject the null was not a product of large standard errors. The substantive levels of imbalance are quite small; see for example Figures A2, A3, A4, and A5 in the SI. ${ }^{19}$ In addition to its value for assessing the presence of imbalances, this is important in considering the sensitivity of analyses performed on the data; the larger the size of the imbalance, the more sensitive estimates are likely to be. Moreover, multiple testing adjustment could be used to adjust the p-values from the placebo checks to control the family wise error rate. ${ }^{20}$

\footnotetext{
${ }^{19}$ In our pooled analysis, moreover, we can statistically reject substantively tiny levels of imbalance.

${ }^{20}$ The family wise error rate is the probability that at least one of the true hypotheses in a family of tested
} 


\section{Demonstrating the Stability of RD Findings}

Finally, the researcher should assess the extent to which her effect estimates are sensitive to specification. As with many empirical approaches, RD designs leave researchers with many degrees of freedom that can lead to specification searching and false-positive results. To mitigate these concerns, the researcher should show results for many different bandwidths and specifications (e.g., difference-in-means, local linear, polynomial, etc.) and also explore sensitivity to the inclusion of pre-treatment covariates. The particular specifications should also be justified with theory and data. For example, a difference-in-means approach with a large bandwidth would likely lead to a large bias, and a high-order polynomial approach with a tiny bandwidth would likely be imprecise and unreliable. Moreover, a local linear specification might be biased if the true regression function is non-linear within the estimation window.

The researcher should also present their data visually in a transparent way that clarifies the appropriateness of the specification and the sensitivity of the results to changes in the specification. At a minimum, we recommend that researches show the "main" RD graph that visualizes the relationship between the outcome and the running variable in the benchmark estimation window. Binned local averages should be used to assess the size of the discontinuity and the empirical shape of the regression functions on both sides of the threshold. We also recommend that researchers superimpose predicted values from a low-order polynomial specification fitted on both sides of the threshold to help assess the appropriate specification. We also recommend graphs like those we present in the Appendix, in which the point estimate for a given specification (e.g., local linear) is plotted across a large range of plausible bandwidths that are consistent with the specification checks, along with 95\% confidence intervals (also see Lee and Lemieux (2010)).

\section{RD Estimates With Imbalance}

How should researchers proceed if they want to estimate electoral effects in the post-war U.S. House or another setting where imbalance is present? So long as they have ruled out plausible hypotheses is rejected. An attractive methodology for this is the free step-down resampling procedure (Westfall and Young 1993; Anderson 2008). This method is typically more powerful than the Bonferroni correction. 
theoretical mechanisms for the imbalance, researchers hoping to estimate electoral effects in the modern U.S. House should proceed in a similar manner to researchers who discover chance imbalances in experimental data. ${ }^{21}$ One might still be able to draw inferences from imbalanced experiments given additional assumptions and covariate adjustment. ${ }^{22}$ One could adjust for imbalance by including lagged incumbency and other pre-treatment variables as covariates in the RD analysis or by pre-processing the data through matching or reweighting before conducting the RD analysis. Alternatively, researchers might consider a "donut" RD design (Almond and Doyle 2011; Barreca et al. 2011), where they exclude the small sample of very close elections where imbalance exists. ${ }^{23}$ It is important to emphasize that all of these fixes require additional assumptions that need to be justified and extraordinary care is required in order to generate inferences given the presence of imbalances. Even if there is something fundamentally problematic about the RD assumptions in the U.S. House, the RD design may still be the best of all imperfect methods for estimating electoral effects in this important setting, and careful RD analysis may still produce better estimates than we could have otherwise obtained with other empirical strategies. As Caughey and Sekhon (2011) write, even in the case of estimating electoral effects in recent U.S. House elections, the RD design appears to be the best option: "Nevertheless, a comparison of the Lee RD estimator with traditional regression approaches to the incumbency advantage reveals that RD relies on weaker assumptions" (pg. 405).

\section{CONCLUSION}

Our results should not induce complacency about the validity of RD designs in close elections. However, they should place the documented imbalances in U.S. House elections in the proper

\footnotetext{
${ }^{21}$ Of course, we cannot be as certain that this imablance has arisen by chance as we could in an experimental setting, and this difference warrants additional prudence.

${ }^{22}$ See Rubin (1973, 1979, 2009), Schochet (2010), and Miratrix, Sekhon and Yu (2013) for discussions of when and how valid inferences can be drawn from imbalanced experimental data.

${ }^{23}$ To be clear, the "donut" has been developed specifically for cases in which there are strong a priori reasons to expect heaping in the running variable. However, one might imagine cases in which the threshold for recounts is known to the researcher, and the researcher believes that recounts are not random. In such a case the researcher might employ a "donut" approach. Nonetheless, it is important to keep in mind that excluding data near the threshold is usually undesirable, since these are the most useful data points in a typical RD. Nevertheless, if these data points are suspect, robustness to their exclusion is a good sign. With sufficient data farther away, but still close, to the threshold, one might still extrapolate to the discontinuity with these points removed.
} 
context. Our perception is that papers showing disproportionate incumbent successes in the U.S. House (particularly Caughey and Sekhon (2011)) have been highly influential among political scientists interested in estimating electoral effects. Absent careful analysis of other electoral contexts, one might conclude that there is something fundamentally problematic about the use of RD to study electoral effects. Evidence of imbalance in the U.S. House may have even made some scholars suspicious of all RD-based studies, to the point where they lend more credence to other approaches. The RD imbalance literature, to our reading, never intended this reaction. Indeed, Caughey and Sekhon (2011) point out that the RD design "still makes weaker assumptions than the usual model-based alternatives" (pg. 406). We agree strongly with this sentiment, and we hope that the validity tests presented in this paper make it clear that the RD design is broadly applicable.

To our knowledge, this paper provides the most thorough and extensive assessment to date of the validity of the regression discontinuity design in electoral settings. Across more than 40,000 closely contested races in many different electoral settings, we find no systematic evidence of sorting or imbalance around electoral thresholds. Conditional on being in a very close election, incumbents are no better at winning than challengers. We hope that these results will bolster confidence in estimates of electoral effects that arise from RD designs, so long as researchers exercise the appropriate level of rigor. We combine this analysis with a consideration of theoretical mechanisms through which the RD assumptions may be violated, arguing that in the case of the U.S. House a plausible mechanism has not yet been proposed; this further strengthens our confidence in the validity of using RD to estimate electoral effects.

To aid in this rigor, we have used our analyses as an opportunity to present our recommendations on "best practices" for applied RD users. When considering the use of the RD in applied work, researchers should begin by considering theoretical reasons for the violation of the RD assumption. If the assumption appears theoretically plausible, researchers should perform a battery of balance tests on pre-treatment covariates and lagged values of the outcome variable, using the same specifications as the analysis on the outcome variable. In performing these tests, researchers should keep in mind that large numbers of tests will lead to some false positives, and so should place special emphasis on the substantive size of any observed im- 
balances and or adjust for multiple testing explicitly. Finally, we recommend that researchers present graphical evidence to support the appropriateness of the specifications used to estimate the effects on the outcome variable of interest and report the estimated effects across a large number of bandwidths and specifications of the running variable.

The RD design provides the opportunity for researchers to assess electoral effects under unusually weak assumptions that mitigate issues of model dependency and omitted variables in all but the most unusual cases. The best practices we propose in this paper should allow researchers to apply the $\mathrm{RD}$, when justified through theory and validation, with the confidence that they have addressed possible problems of imbalance in their data. Though the RD's assumption may not always hold, it continues to offer the most plausible, least model-dependent estimates for a variety of electoral effects across numerous electoral settings. 


\section{REFERENCES}

Ade, Florian and Ronny Freier. 2011. "Divided Government Versus Incumbency Externality Effect: Quasi-Experimental Evidence on Multiple Voting Decisions." DIW Berlin Discussion Paper No. 1121.

Aidt, Toke, Miriam A Golden and Devesh Tiwari. 2011. "Incumbents and Criminals in the Indian National Legislature.". Unpublished Manuscript.

Almond, Douglas and Joseph J Doyle. 2011. "After Midnight: A Regression Discontinuity Design in Length of Postpartum Hospital Stays." American Economic Journal: Economic Policy 3(3):1-34.

Anderson, Michael L. 2008. "Multiple inference and gender differences in the effects of early intervention: A reevaluation of the Abecedarian, Perry Preschool, and Early Training Projects." Journal of the American statistical Association 103(484).

Ariga, Kenichi. 2010. Entrenched Incumbents, Irresponsible Parties? Comparative Analysis of Incumbency Advantage Across Different Electoral Systems PhD thesis University of Michigan.

Barreca, Alan I., Melanie Guldi, Jason M. Lindo and Glen R. Waddell. 2011. "Saving Babies? Revisiting the Effect of Very Low Birth Weight Classification." The Quarterly Journal of Economics 126(4):2117-2123.

Boas, Taylor C and F Daniel Hidalgo. 2011. "Controlling the Airwaves: Incumbency Advantage and Community Radio in Brazil." American Journal of Political Science 55(4):869-885.

Broockman, David E. 2009. "Do Congressional Candidates Have Reverse Coattails? Evidence From A Regression Discontinuity Design." Political Analysis 17(4):418-434.

Butler, Daniel Mark. 2009. "A Regression Discontinuity Design Analysis of the Incumbency Advantage and Tenure in the U.S. House." Electoral Studies 28(1):123-128.

Caughey, Devin and Jasjeet S Sekhon. 2011. "Elections and the Regression Discontinuity Design: Lessons from Close US House Races, 1942-2008." Political Analysis 19(4):385-408.

Cellini, Stephanie Riegg, Fernando Ferreira and Jesse Rothstein. 2010. "The Value of School Facility Investments: Evidence From a Dynamic Regression Discontinuity Design." The Quarterly Journal of Economics 125(1):215-261.

Dal Bó, Ernesto, Pedro Dal Bó and Jason Snyder. 2009. "Political Dynasties." The Review of Economic Studies 76(1):115-142.

Dell, Melissa. 2012. "Trafficking Networks and the Mexican Drug War.". Unpublished Manuscript.

DiNardo, John and David S Lee. 2004. "Economic Impacts of New Unionization On Private Sector Employers: 1984-2001." The Quarterly Journal of Economics 119(4):1383-1441. 
Eggers, Andrew C. and Jens Hainmueller. 2009. "MPs For Sale? Returns to Office in Postwar British Politics." American Political Science Review 103(4):513.

Enos, Ryan and Eitan Hersh. 2013. "Elite Perceptions of Electoral Closeness: Fear in the Face of Uncertainty or Overconfidence of True Believers." MPSA Annual Meeting Paper.

Ferreira, Fernando and Joseph Gyourko. 2009. "Do Political Parties Matter? Evidence from U.S. Cities." The Quarterly Journal of Economics 124(1):399-422.

Folke, Olle and James M. Snyder Jr. 2012. "Gubernatorial Midterm Slumps." American Journal of Political Science 56(4):931-948.

Gagliarducci, Stefano and M Daniele Paserman. 2012. "Gender Interactions Within Hierarchies: Evidence from the Political Arena." The Review of Economic Studies 79(3):1021-1052.

Gerber, Elisabeth R and Daniel J Hopkins. 2011. "When Mayors Matter: Estimating the Impact of Mayoral Partisanship on City Policy." American Journal of Political Science $55(2): 326-339$.

Grimmer, Justin, Eitan Hirsh, Brian Feinstein and Daniel Carpenter. 2012. "Are Close Elections Random?" Working Paper.

Hahn, Jinyong, Petra Todd and Wilbert Van der Klaauw. 2001. "Identification and Estimation of Treatment Effects with a Regression-Discontinuity Design." Econometrica 69(1):201-209.

Hainmueller, Jens and Holger Lutz Kern. 2008. "Incumbency As a Source of Spillover Effects In Mixed Electoral Systems: Evidence From a Regression-Discontinuity Design." Electoral Studies 27(2):213-227.

Horiuchi, Yusaku and Andrew Leigh. 2009. "Estimating Incumbency Advantage: Evidence from Multiple Natural Experiments.". Unpublished Manuscript.

Imbens, Guido W. and Thomas Lemieux. 2008. "Regression Discontinuity Designs: A Guide to Practice." Journal of Econometrics 142(2):615-635.

Katz, Jonathan N and Gary King. 1999. "A Statistical Model for Multiparty Electoral Data." American Political Science Review pp. 15-32.

Kendall, Chad and Marie Rekkas. 2012. "Incumbency advantages in the Canadian Parliament." Canadian Journal of Economics/Revue canadienne d'économique 45(4):1560-1585.

Klarner, Carl. 2008. "Forecasting the 2008 US House, Senate and Presidential Elections at the District and State Level." PS: Political Science 85 Politics 41(04):723-728.

Klašnja, Marko and Rocío Titiunik. 2013. "Incumbency Disadvantage In Weak Party Systems: Evidence from Brazil.". Unpublished Manuscript.

Lee, David S. 2008. "Randomized Experiments From Non-Random Selection in U.S. House Elections." Journal of Econometrics 142(2):675-697. 
Lee, David S, Enrico Moretti and Matthew J. Butler. 2004. "Do Voters Affect or Elect Policies? Evidence from the U.S. House." The Quarterly Journal of Economics 119(3):807-859.

Lee, David S and Thomas Lemieux. 2010. "Regression Discontinuity Designs in Economics." The Journal of Economic Literature 48(2):281-355.

Lehoucq, Fabrice. 2003. "Electoral Fraud: Causes, Types, and Consequences." Annual Review of Political Science 6(1):233-256.

Leigh, Andrew. 2008. "Estimating the Impact of Gubernatorial Partisanship on Policy Settings and Economic Outcomes: A Regression Discontinuity Approach." European Journal of Political Economy 24(1):256-268.

Linden, Leigh L. 2004. "Are Incumbents Really Advantaged? The Preference for NonIncumbents in Indian National Elections.". Unpublished Manuscript.

McCrary, Justin. 2008. "Manipulation of the Running Variable in the Regression Discontinuity Design: A Density Test." Journal of Econometrics 142(2):698-714.

Miratrix, Luke W., Jasjeet S. Sekhon and Bin Yu. 2013. "Adjusting Treatment Effect Estimates by Post-Stratification in Randomized Experiments." Journal of the Royal Statistical Society: Series B (Statistical Methodology) 75(2):369-396.

Pettersson-Lidbom, Per. 2008. "Do Parties Matter For Economic Outcomes? A RegressionDiscontinuity Approach." Journal of the European Economic Association 6(5):1037-1056.

Querubin, Pablo. 2011. "Political Reform and Elite Persistence: Term Limits and Political Dynasties in the Philippines." Unpublished.

Rubin, Donald B. 1973. "The Use of Matched Sampling and Regression Adjustment to Remove Bias in Observational Studies." Biometrics 29(1):pp. 185-203.

Rubin, Donald B. 1979. "Using Multivariate Matched Sampling and Regression Adjustment to Control Bias in Observational Studies." Journal of the American Statistical Association $74(366 \mathrm{a}): 318-328$.

Rubin, Donald B. 2009. "Should Observational Studies Be Designed To Allow Lack Of Balance In Covariate Distributions Across Treatment Groups?" Statistics in Medicine 28(9):14201423.

Schochet, Peter Z. 2010. "Is Regression Adjustment Supported by the Neyman Model For Causal Inference?" Journal of Statistical Planning and Inference 140(1):246-259.

Simpser, Alberto. 2013. Why Governments and Parties Manipulate Elections: Theory, Practice, and Implications. Cambridge University Press.

Snyder, Jason. 2005. "Detecting Manipulation in U.S. House Elections.". Unpublished Manuscript. 
Thistlethwaite, Donald L and Donald T Campbell. 1960. "Regression-Discontinuity Analysis: An Alternative to the Ex Post Facto Experiment." Journal of Educational psychology 51(6):309-317.

Trounstine, Jessica. 2011. "Evidence of a Local Incumbency Advantage." Legislative Studies Quarterly 36(2):255-280.

Uppal, Yogesh. 2009. "The Disadvantaged Incumbents: Estimating Incumbency Effects In Indian State Legislatures." Public Choice 138(1-2):9-27.

Uppal, Yogesh. 2010. "Estimating Incumbency Effects In U.S. State Legislatures: A QuasiExperimental Study." Economics 8 Politics 22(2):180-199.

Vogl, Tom. 2012. "Race and the Politics of Close Elections." Working Paper Princeton University .

Westfall, Peter H. and Stanley S. Young. 1993. Resampling-based multiple testing: Examples and methods for p-value adjustment. New York, NY: Wiley. 
Figure 1: Proportion of previous Democratic wins as function of Democratic vote margin, U.S. House 1946-2010

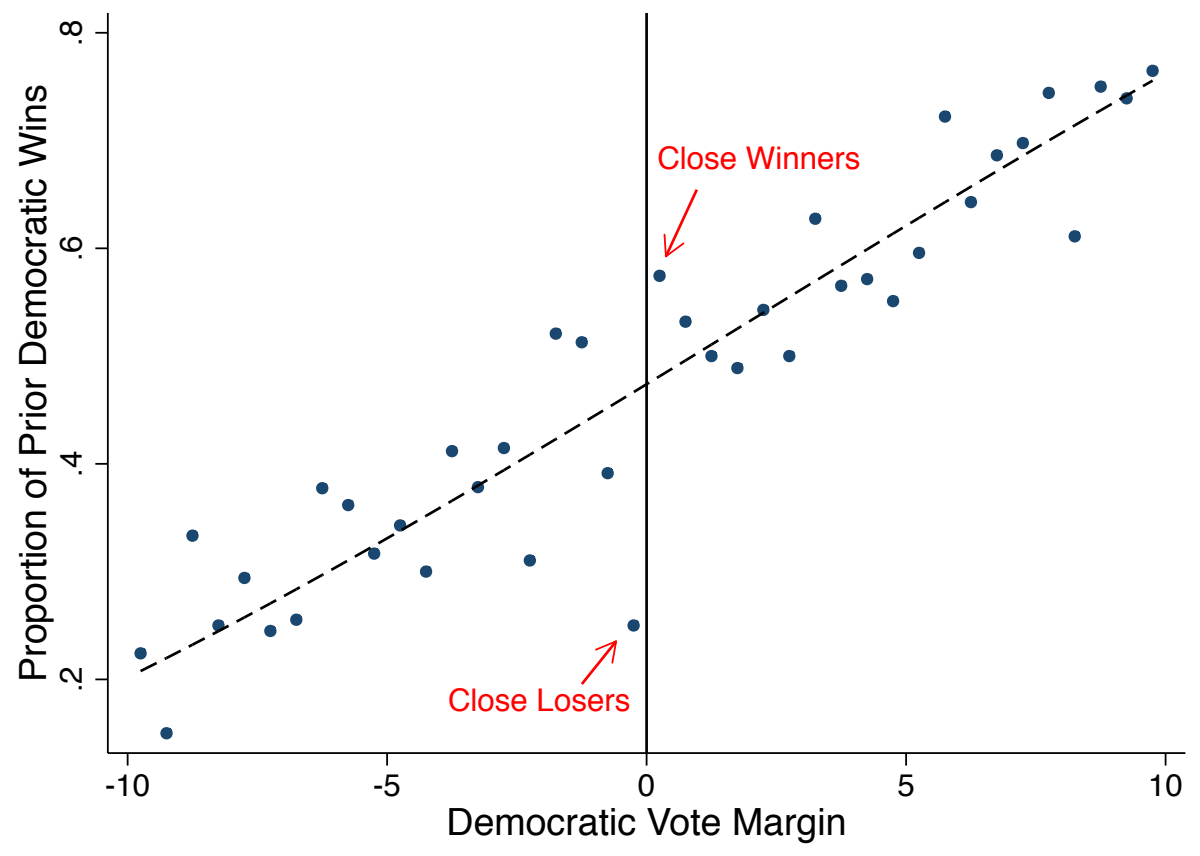


Figure 2: Summary of tests in Table 3
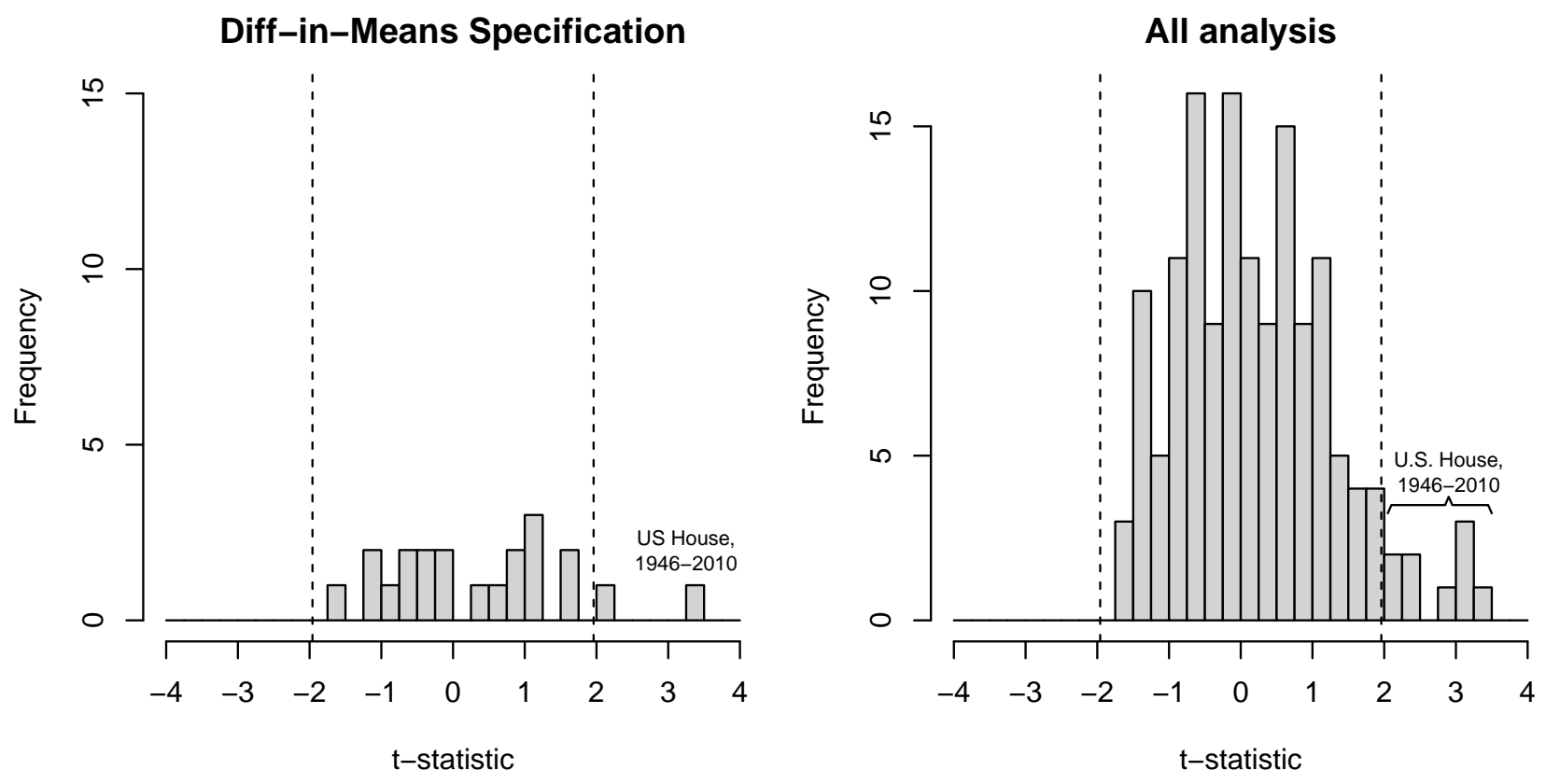
Figure 3: Summary of tests in Table 4
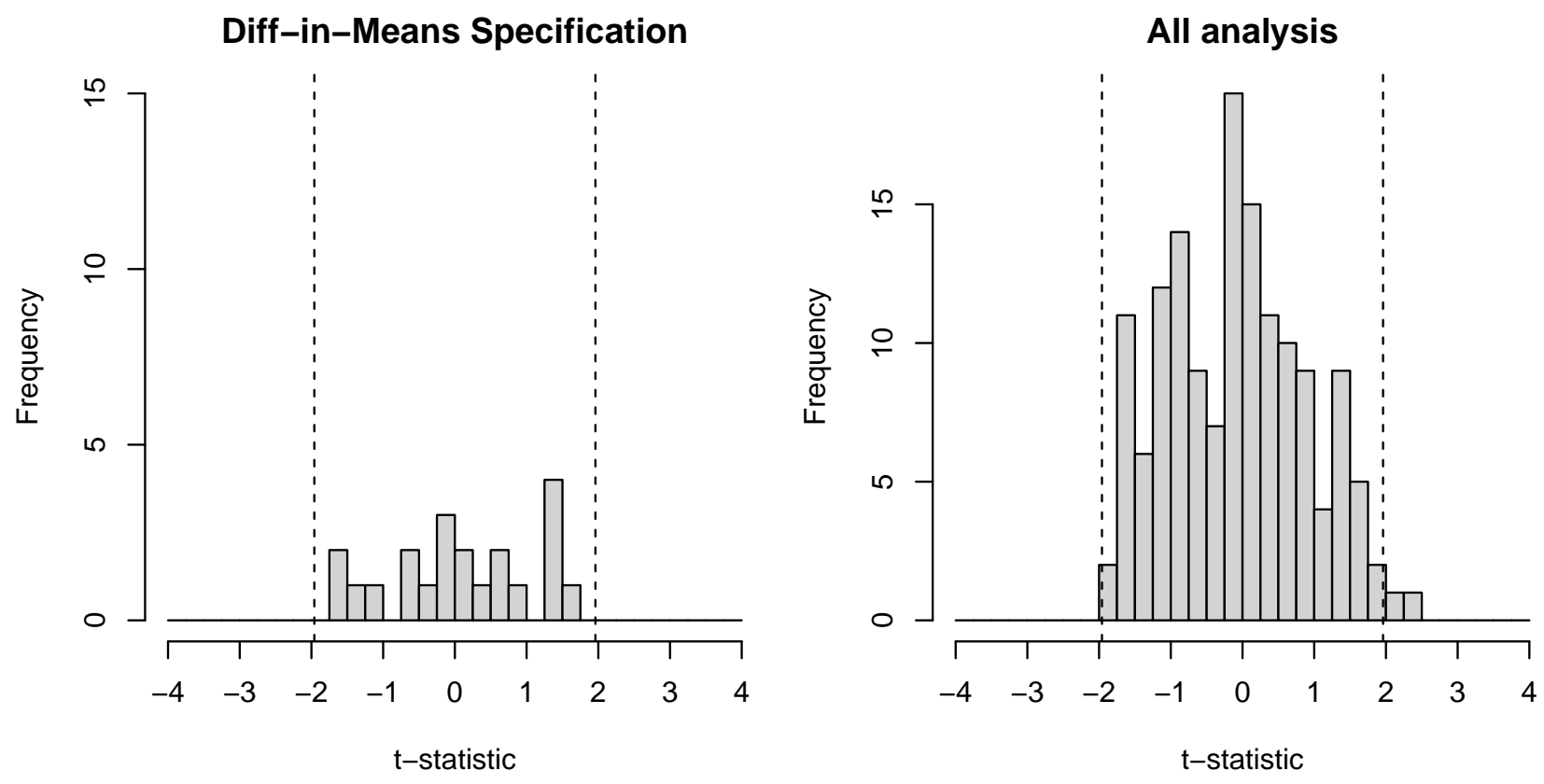
Table 1: p-values from placebo tests in Caughey and Sekhon (2011) with and without controlling for incumbency. These tests cover all those with a reported imbalance in Caughey and Sekhon (2011).

\begin{tabular}{|l|c|c|}
\hline $\begin{array}{l}\text { Dependent } \\
\text { Variable }\end{array}$ & $\begin{array}{c}\text { Original } \\
\text { Specification }\end{array}$ & $\begin{array}{c}\text { Including } \\
\text { Dem Win } t-1\end{array}$ \\
\hline Democratic Win $t-1$ & .00 & - \\
Democratic \% Vote $t-1$ & .10 & .33 \\
Democratic \% Margin $t-1$ & .03 & .58 \\
Incumbent D1 Nominate & .00 & .60 \\
Democratic Incumb in Race & .00 & .58 \\
Republican Incumb in Race & .00 & .44 \\
Democratic \# Previous Terms & .08 & .74 \\
Republican \# Previous Terms & .00 & .10 \\
Democratic Experience Adv & .00 & .70 \\
Republican Experience Adv & .00 & .31 \\
Partisan Swing & .00 & .24 \\
CQ Rating & .00 & .47 \\
Democratic Spending \% & .01 & .22 \\
Democratic Donation \% & .07 & .53 \\
\hline
\end{tabular}

Note: Cell entries are p-values for the variable Democratic Win $t$ from linear regressions on the set of races in a 0.5 point window, with robust standard errors. In the column labeled Original Specification the only regressor is Democratic Win t. In the column labeled Including Democratic Win $t-1$ the two regressors are Democratic Win $t$ and Democratic Win $t$-1. For full variable definitions see Caughey and Sekhon (2011). 
Table 2: Data analyzed

\begin{tabular}{|l|c|c|c|c|}
\hline \multirow{2}{*}{ Setting } & \multicolumn{3}{|c|}{ Bandwidth } & Reference \\
& 10 & 2 & 1 & party \\
\hline U.S., House of Reps, 1880-2010 & 5087 & 1084 & 567 & \\
U.S., House of Reps, 1880-1944 & 3232 & 731 & 380 & Democratic \\
U.S., House of Reps, 1946-2010 & 1855 & 353 & 187 & Democratic \\
U.S., Statewide, 1946-2010 & 2202 & 498 & 250 & Democratic \\
U.S., State Legislature, 1990-2010 & 5953 & 1204 & 582 & Democratic \\
U.S., Mayors, 1947-2007 & 457 & 108 & 51 & Democratic \\
Canada, Commons, 1867-2011 & 2553 & 576 & 278 & Liberal \\
Canada, Commons, 1867-1911 & 759 & 205 & 102 & Liberal \\
Canada, Commons, 1921-2011 & 1794 & 371 & 176 & Liberal \\
U.K., Commons, 1918-2010 & 3414 & 675 & 336 & Conservative \\
U.K., Local Councils, 1946-2010 & 10881 & 2123 & 1047 & Conservative \\
Germany, Bundestag, 1953-2009 & 1260 & 262 & 131 & CDU/CSU \\
Bavaria, Mayors, 1948-2009 & 928 & 195 & 87 & CSU \\
France, Natl Assembly, 1958-2007 & 872 & 215 & 104 & Socialist \\
France, Municipalities, 2008 & 458 & 104 & 59 & Left \\
Australia, House of Reps, 1987-2007 & 349 & 73 & 39 & Labor \\
New Zealand, Parliament, 1949-1987 & 330 & 57 & 27 & National \\
India, Lower House, 1977-2004 & 1093 & 222 & 106 & Congress \\
Brazil, Mayors, 2000-2008 & 1270 & 265 & 143 & PMDB \\
Mexico, Mayors, 1970-2009 & 4016 & 801 & 404 & PRI \\
\hline All Races Pooled & 41124 & 8463 & 4212 & - \\
\hline
\end{tabular}

Note: See Supporting Information Appendix A for details on each data set. The bandwidths are defined such that a bandwidth of 1 includes all elections where the reference party won or lost by a margin of 1 point or less. 
Table 3: Placebo tests: p-values for "effect" of party winning at time $t$ on party winning at time $t-1$

\begin{tabular}{|l|c|c|c|c|c|c|r|}
\hline & \multicolumn{2}{|c|}{ Diff-in-Means } & \multicolumn{2}{|c|}{ Local Linear } & \multicolumn{2}{c|}{ Polynomial } \\
\hline \multicolumn{1}{|c|}{ Bandwidth } & 0.5 & 1 & 1 & 2 & 5 & 5 & 10 \\
\hline U.S., House of Reps, 1880-2010 & 0.11 & 0.07 & 0.46 & 0.30 & 0.33 & 0.30 & 0.33 \\
U.S., House of Reps, 1880-1944 & 0.70 & 1.00 & 0.59 & 0.36 & 0.90 & 0.48 & 0.62 \\
U.S., House of Reps, 1946-2010 & 0.00 & 0.00 & 0.04 & 0.00 & 0.07 & 0.00 & 0.02 \\
U.S., Statewide, 1946-2010 & 0.55 & 0.79 & 0.43 & 0.38 & 0.56 & 0.50 & 0.10 \\
U.S., State Legislature, 1990-2010 & 0.37 & 0.52 & 0.32 & 0.95 & 0.59 & 0.78 & 0.77 \\
U.S., Mayors, 1947-2007 & - & 0.96 & - & 0.81 & 0.88 & 0.37 & 0.62 \\
Canada, Commons, 1867-2011 & 0.29 & 0.50 & 0.32 & 0.18 & 0.09 & 0.59 & 0.17 \\
Canada, Commons, 1867-1911 & 0.59 & 0.22 & 0.81 & 0.21 & 0.19 & 0.60 & 0.18 \\
Canada, Commons, 1921-2011 & 0.30 & 0.88 & 0.18 & 0.39 & 0.17 & 0.71 & 0.35 \\
U.K., Commons, 1918-2010 & 0.33 & 0.09 & 0.59 & 0.61 & 0.08 & 0.92 & 0.12 \\
U.K., Local Councils, 1946-2010 & 0.24 & 0.06 & 0.44 & 0.27 & 0.22 & 0.17 & 0.68 \\
Germany, Bundestag, 1953-2009 & 0.71 & 0.54 & 0.79 & 0.48 & 1.00 & 0.74 & 0.84 \\
Bavaria, Mayors, 1948-2009 & 0.13 & 0.38 & 0.21 & 0.39 & 0.16 & 0.19 & 0.30 \\
France, Natl Assembly, 1958-2007 & 0.27 & 0.79 & 0.33 & 0.55 & 0.53 & 0.47 & 0.23 \\
France, Municipalities, 2008 & - & 0.31 & - & 0.37 & 0.14 & 0.52 & 0.24 \\
Australia, House of Reps, 1987-2007 & - & - & - & 1.00 & 0.55 & 0.50 & 0.92 \\
New Zealand, Parliament, 1949-1987 & - & - & - & - & 0.75 & 0.86 & 0.69 \\
India, Lower House, 1977-2004 & 0.49 & 0.38 & 0.54 & 0.98 & 0.20 & 0.97 & 0.86 \\
Brazil, Mayors, 2000-2008 & 0.81 & 0.81 & 0.61 & 0.58 & 0.78 & 0.64 & 0.97 \\
Mexico, Mayors, 1970-2009 & 0.69 & 0.96 & 0.39 & 0.68 & 0.93 & 0.93 & 0.60 \\
\hline All Races Pooled & 0.22 & 0.02 & 0.92 & 0.59 & 0.16 & 0.46 & 0.75 \\
\hline
\end{tabular}

Note: Each entry gives the p-value of a two-tailed test of the hypothesis that the coefficient on Treatment is zero. Results not shown if there are insufficient data points within a given bandwidth, to avoid biased or uninformative inferences. Sample size cutoffs are 40, 60, and 100 for difference-in-means, local linear, and polynomial. Results in italics indicate that the point estimate is the opposite of what one would expect if incumbents disproportionately win close elections. Robust standard errors used in all cases. Standard errors clustered by state-year for U.S. Statewide offices. 
Table 4: Placebo tests: p-values for "effect" of party winning at time $t$ on party vote margin at time $t-1$

\begin{tabular}{|l|c|c|c|c|c|c|r|}
\hline & \multicolumn{2}{|c|}{ Diff-in-Means } & \multicolumn{2}{|c|}{ Local Linear } & \multicolumn{2}{c|}{ Polynomial } \\
\hline \multicolumn{1}{|c|}{ Bandwidth } & 0.5 & 1 & 1 & 2 & 5 & 5 & 10 \\
\hline U.S., House of Reps, 1880-2010 & 0.21 & 0.15 & 0.81 & 0.51 & 0.37 & 0.77 & 0.81 \\
U.S., House of Reps, 1880-1944 & 0.91 & 0.85 & 0.77 & 0.46 & 0.95 & 0.39 & 0.58 \\
U.S., House of Reps, 1946-2010 & 0.15 & 0.04 & 0.63 & 0.16 & 0.21 & 0.29 & 0.41 \\
U.S., Statewide, 1946-2010 & 0.84 & 0.69 & 0.81 & 0.82 & 0.98 & 0.97 & 0.29 \\
U.S., State Legislature, 1990-2010 & 0.75 & 0.78 & 0.92 & 0.91 & 0.91 & 0.89 & 0.59 \\
U.S., Mayors, 1947-2007 & - & 0.11 & - & 0.22 & 0.42 & 0.09 & 0.10 \\
Canada, Commons, 1867-2011 & 0.12 & 0.31 & 0.13 & 0.10 & 0.06 & 0.29 & 0.08 \\
Canada, Commons, 1867-1911 & 0.26 & 0.17 & 0.38 & 0.27 & 0.08 & 0.53 & 0.12 \\
Canada, Commons, 1921-2011 & 0.21 & 0.51 & 0.20 & 0.17 & 0.17 & 0.35 & 0.19 \\
U.K., Commons, 1918-2010 & 0.16 & 0.11 & 0.65 & 0.43 & 0.58 & 0.67 & 0.46 \\
U.K., Local Councils, 1946-2010 & 0.10 & 0.02 & 0.33 & 0.12 & 0.40 & 0.08 & 0.35 \\
Germany, Bundestag, 1953-2009 & 0.95 & 0.45 & 0.50 & 0.81 & 0.29 & 0.98 & 0.37 \\
Bavaria, Mayors, 1948-2009 & 0.10 & 0.39 & 0.12 & 0.30 & 0.10 & 0.23 & 0.26 \\
France, Natl Assembly, 1958-2007 & 0.57 & 0.39 & 0.54 & 0.26 & 0.76 & 0.34 & 0.92 \\
France, Municipalities, 2008 & - & 0.46 & - & 0.83 & 0.11 & 0.92 & 0.48 \\
Australia, House of Reps, 1987-2007 & - & - & - & 0.49 & 0.30 & 0.36 & 0.18 \\
New Zealand, Parliament, 1949-1987 & - & - & - & - & 0.09 & 0.77 & 0.31 \\
India, Lower House, 1977-2004 & 0.77 & 0.78 & 0.40 & 0.78 & 0.21 & 0.88 & 0.89 \\
Brazil, Mayors, 2000-2008 & 0.47 & 0.77 & 0.25 & 0.33 & 0.52 & 0.32 & 0.95 \\
Mexico, Mayors, 1970-2009 & 0.99 & 0.77 & 0.83 & 0.98 & 0.35 & 0.73 & 0.42 \\
\hline All Races Pooled & 0.46 & 0.25 & 0.95 & 0.88 & 0.95 & 0.95 & 0.50 \\
\hline
\end{tabular}

Note: See text for explanation of tests and notes to Table 4 for details on presentation. 
Table 5: McCrary (2008) tests: p-values for null hypothesis of equal density on opposite sides of the threshold

\begin{tabular}{|l|c|c|c|}
\hline & Incumbent & Non-Incumb & Pooled \\
\hline U.S., House of Reps, 1880-2010 & 0.80 & 0.85 & 0.95 \\
U.S., House of Reps, 1880-1944 & 0.60 & 0.57 & 0.38 \\
U.S., House of Reps, 1946-2010 & 0.07 & 0.18 & 0.05 \\
U.S., Statewide, 1946-2010 & 0.43 & 0.47 & 0.26 \\
U.S., State Legislature, 1990-2010 & 0.83 & 0.42 & 0.41 \\
U.S., Mayors, 1947-2007 & 0.76 & 0.13 & 0.39 \\
Canada, Commons, 1867-2011 & 0.34 & 0.62 & 0.23 \\
$\quad$ Canada, Commons, 1867-1911 & 0.65 & 0.14 & 0.38 \\
Canada, Commons, 1921-2011 & 0.25 & 0.59 & 0.76 \\
U.K., Commons, 1918-2010 & 0.44 & 0.07 & 0.10 \\
U.K., Local Councils, 1946-2010 & 0.73 & 0.32 & 0.46 \\
Germany, Bundestag, 1953-2009 & 0.49 & 0.33 & 0.64 \\
Bavaria, Mayors, 1948-2009 & 0.26 & 0.83 & 0.93 \\
France, Natl Assembly, 1958-2007 & 0.62 & 0.03 & 0.12 \\
France, Municipalities, 2008 &. & 0.91 & 0.10 \\
Australia, House of Reps, 1987-2007 & 0.72 & 0.13 & 0.13 \\
New Zealand, Parliament, 1949-1987 & 0.40 & 1.00 & 0.78 \\
India, Lower House, 1977-2004 & 0.79 & 0.40 & 0.58 \\
Brazil, Mayors, 2000-2008 & 0.45 & 0.37 & 0.83 \\
Mexico, Mayors, 1970-2009 & 0.94 & 0.63 & 0.85 \\
\hline All Races Pooled & 0.81 & 0.42 & 0.62 \\
\hline
\end{tabular}

Note: See text for explanation of test and notes to Table 4 for details on presentation. 


\section{Supporting Information Appendix A: Data sources And Definitions}

\section{A. U.S. State Legislative Elections}

The U.S. State Legislative Election data comes from ICPSR Study 34297 (http://www.icpsr.umich.edu/ icpsrweb/ICPSR/studies/34297). The data set provides election returns for all fifty states, 1967-2010. We exclude nonpartisan elections (most notably Nebraska's unicameral legislature) along with multi-member districts. We subset to outcomes from 1990-2010 in order to use only the most reliable information on off-cycle redistrictings. While state legislatures are nominally redistricted each decade in the year ending in '2', there have been a significant number of redistrictings in other years due to court cases and other extenuating circumstances. The data on redistricting from 1990 to present comes from Carl Klarner. This leaves us with 65,199 observations across 49 states.

\section{B. U.S. Mayoral Elections}

The U.S. Mayoral data was originally collected for Ferreira and Gyourko (2009) and has been extended by those authors in subsequent work. The extended data set contains mayoral election results for the years 1945-2007 in 834 cities, which includes non-partisan elections and elections in which members of the same party faced each other. We restrict to races where a Democrat faced a Republican, which leaves 2,396 observations spanning 494 cities.

\section{Canadian House of Commons Elections}

Data is provided by the Constituency-Level Elections Archive for elections to the House of Commons of Canada between 1867 and 2011. ${ }^{24}$ The reference party is the Liberal Party of Canada. Members are elected in single member constituencies (ridings) by simple plurality. We exclude the few double-member ridings that existed in some provinces in the early periods. Redistricting is conducted by an independent commission every ten years. A riding is included in the analysis only when the riding boundary remains unchanged from the previous election. Data on historical boundary changes is provided by the Parliament of Canada, History of Federal Ridings Since 1867.

\section{British House of Commons Elections}

Data is provided by the Constituency-Level Elections Archive for elections to the British House of Commons between 1918 and 1997. Data for the elections in 2001, 2005, and 2010 are provided by the Electoral Commission and compiled by Rallings and Thrasher at the LGC Elections Centre at the University of Plymouth. The reference party is the Conservative Party. Members are elected in single member constituencies by simple plurality. We exclude the few multi-member constituencies that existed prior to 1950. Redistricting is conducted by a boundary commission every 8-12 years. A constituency is included in the analysis only when

\footnotetext{
${ }^{24}$ Ken Kollman, Allen Hicken, Daniele Caramani, and David Backer. Constituency-Level Elections Archive (CLEA; www.electiondataarchive.org), December 17, 2012 [dataset]. Ann Arbor, MI: University of Michigan, Center for Political Studies [producer and distributor].
} 
the constituency name remains unchanged from the previous election; we cleaned and checked constituency names for consistency across elections. In the data we find that there are 1,850 unique constituencies across the 25 elections. Most of them experienced redistricting at some point during the sample period. The median constituency remains unchanged for seven elections.

\section{E. British Local Elections}

Data comes from the British Local Election Database published by Rallings, Thrasher, and Ware. ${ }^{25}$ The reference party is the Conservatives. Analysis is based on single-member elections to county councils, district councils, and unitary authorities in England, Scotland, and Wales in the period 1945-2003. Wards are included in the analysis only when the ward boundary is the same as in the previous election.

\section{F. German Bundestag Elections}

Data is provided by the Federal Returning Officer (Bundeswahlleiter). The reference party is the Christian Democratic Union of Germany (CDU) together with its Bavarian sister party the Christian Social Union of Bavaria (CSU). Germany has a mixed electoral system where, since 1953, voters have two votes. The first vote is for a direct candidate for the constituency and the candidate who receives a simple plurality of first votes gets the direct mandate to serve in the Bundstag (SMD tier). Each constituency returns a single member. The second vote is for a party list and determines the proportion of seats a party receives in the Bundestag (PR tier). Analysis is based on the SMD tier races for the 12 elections between 1953 to 2009. Periodic redistricting is conducted by an independent election commission. A race is included in the analysis only when the constituency area remains unchanged from the previous election. Data on constituency areas is obtained from various years of the German election law (Änderung des Bundeswahlgesetzes 1949, 1964, 1972, 1976, 1979, 1985, 1989, 1990, 1993, 1996, 2001, 2005, 2008). Periodic redistricting often involves only a small subset of constituencies. 84 constituencies remain constant for all 12 elections. The median constituency remains unchanged for four elections.

\section{G. Bavarian Mayoral Elections}

Data has been collected, and provided to us, by Florian Ade and Ronny Freier and was originally used in Ade and Freier (2011). The data covers about 25000 mayor elections in the state of Bavaria for the time period 1946-2009. A feature of these elections is important for the correct implementation of a correct analysis is the presence of a second (or run-off) ballot. If no candidate reaches the majority of $50 \%$ in the first round, a second round is held between the two leading candidates. If there is such a second round we use that in our analysis. We use the CSU as the reference party in our analysis. Also, we restrict the sample to contested elections with the top two candidates being from different parties. These restrictions leave us with a sample of a little bit less than 10000 observations.

\footnotetext{
${ }^{25}$ Rallings, C.S., Thrasher, M.A.M. and Ware, L., British Local Election Database, 1889-2003 [computer file]. Colchester, Essex: UK Data Archive [distributor], June 2006. SN: 5319, http://dx.doi.org/10.5255/ UKDA-SN-5319-1.
} 


\section{H. French National Assembly elections}

Data is provided by CDSP (Centre de Données Socio-politiques) of Sciences Po and CNRS. The reference party is the Socialists. From 1958 to 1981 the results are aggregated by party label, meaning that the vote totals are incorrect in cases where multiple candidates from the same party compete. Analysis of the data from 1988 to 2007 indicates that this happened so rarely as to not pose a serious problem: two candidates of the same party label appeared in the second round in only about .6\% of cases. (In the first round, which is rarely decisive, the rate was about $3.5 \%$.) The election of 1986 was conducted via party-list proportional representation and was followed by a major redistricting; we thus omit the 1986 election and treat the periods before and after separately. (Other episodes of minor redistricting are dealt with by dropping observations in which the lagged outcomes took place under different boundaries.)

Legislative elections in France take place in two-round contests: if no candidate wins a majority of votes in the first round, then a second round is held in which all candidates receiving less than a certain amount of support are eliminated. (This threshold is currently $12.5 \%$ of registered voters; between 1966 and 1976 it was $10 \%$ of registered voters and between 1958 and 1966 it was 5\% of votes cast.) We define the running variable based on the decisive round - the round in which the winner was declared.

\section{French municipal elections}

Data is provided by the Ministry of the Interior. Analysis is based on the 2008 election in cities with at least 3,500 inhabitants. The electoral system in this setting is not single-member plurality as it is in the other settings we study: municipal elections in France take place between lists of candidates rather than between individual candidates, and the electoral system is nominally proportional rather than plurality rule. Including these elections in the analysis makes sense, however, because the electoral system confers a large "winner's bonus" of $50 \%$ of the seats to the winning list (the remainder of seats are distributed proportionally among all of the lists), such that the winner of a close contest between two lists ends up with a large majority and can thus choose the mayor. If sorting is a problem in SMP elections, therefore, one would expect to find it here as well.

Due to the large number of parties and inconsistent labeling of parties across years, we use as the reference party the "Left", meaning lists labeled by the Ministry of the Interior in 2008 as Socialist, Communist, "miscellaneous Left", extreme Left, Green, or union of the Left; in 2001, the corresponding labels are Left, "miscellaneous Left", extreme Left, and Green.

As in legislative elections in France, municipal elections take place in two rounds. (At the municipal level, lists winning less than $10 \%$ of the vote are eliminated.) We take the same approach, basing the running variable on the decisive round.

\section{J. Australian House of Representatives Elections}

Data on Australian House of Representatives Elections from 1987 to 2007 is from the Australian Electoral Commission as assembled and cleaned by Horiuchi and Leigh (2009). The reference party is the Australian Labor Party. Australia has essentially a two-party system with the Labor Party on the left and several other 
parties typically forming a coalition on the right. Voting is by a preferential system (or instant runoff) where voters rank candidates, allowing for the calculation of a two-party preferred vote for the top two candidates. Our analysis focuses on the Labor Party's share of the two-party preferred vote.

Redistricting in Australia is conducted by an independent commission before every election, but the changes are typically small. Between the 1990 and 2010 elections (when redistricting data is available) 59 percent of districts were not changed at all before an upcoming elections, only 26 percent of districts were changed by $10 \%$ or more (meaning that $10 \%$ of the voters in that election were new to the district), 16 percent of districts were changed by $20 \%$ or more, 10 percent of districts were changed $30 \%$ or more, 6 percent of districts were changed by $40 \%$ or more, and only 3 percent of districts were changes by $50 \%$ or more. We cannot restrict our analysis based on the extent of redistricting in a particular electoral division or year, because the placebo outcomes may have potentially influenced the redistricting process. However, given the minimal extent of redistricting in each election, attenuation resulting from redistricting is likely to be minimal.

\section{K. New Zealand House of Representatives}

Data is provided by the Constituency-Level Elections Archive for elections to the New Zealand House of Representatives between 1946 and 1987. ${ }^{26}$ The reference party is the New Zealand National Party. Members are elected in single member districts by simple plurality. Redistricting is conducted by an independent commission every fifth year. A district remains in the analysis only if its name has not changed from the previous election, which we use to approximate large redistricting events.

\section{Indian Lower House Elections}

Data is provided by the Election Commission of India for elections to the lower house of parliament (Lok Sabha) between 1977 and 2004. The reference party is the Indian National Congress (INC). Candidates are directly elected in single member constituencies by simple plurality. Constituency boundaries remain unchanged during this period (apart from a few changes in the state boundaries).

\section{Brazilian Mayoral Elections}

Data is provided by the Supreme Electoral Tribunal (Tribunal Superior Eleitoral) for mayoral elections in 2000, 2004, and 2008. The reference party is the Brazilian Democratic Movement Party (Partido do Movimento Democrático Brasileiro). Mayors are elected by simple plurality in each municipality. The vast majority of municipalities only have one round, but large municipalities can have a run-off election and for those municipalities we use the results from the first round. There is no redistricting during this period. In a very small number of cases the municipality names change and these cases are excluded (following cleaning to identify unique names across election years).

\footnotetext{
${ }^{26}$ Ken Kollman, Allen Hicken, Daniele Caramani, and David Backer. Constituency-Level Elections Archive (CLEA; www.electiondataarchive.org), December 17, 2012 [dataset]. Ann Arbor, MI: University of Michigan, Center for Political Studies [producer and distributor].
} 


\section{N. Mexican Municipal Elections}

State-by-state municipal election data for Mexico was collected by Melissa Dell for Dell (2012) among other studies. The original data "are from Mexico Electoral-Banamex and electoral results published by the Electoral Tribunals of each state. For 11 states, data on the total number of eligible voters, required to calculate turnout, are not reported" (Dell 2012: 34). Elections are multi-party; we use PRI as the party of interest. 


\section{Supporting Information Appendix B: GraphS}

Figure B1: Testing for imbalance in lagged incumbent victory using the difference-in-means and the local linear regression estimator (All Races Pooled).

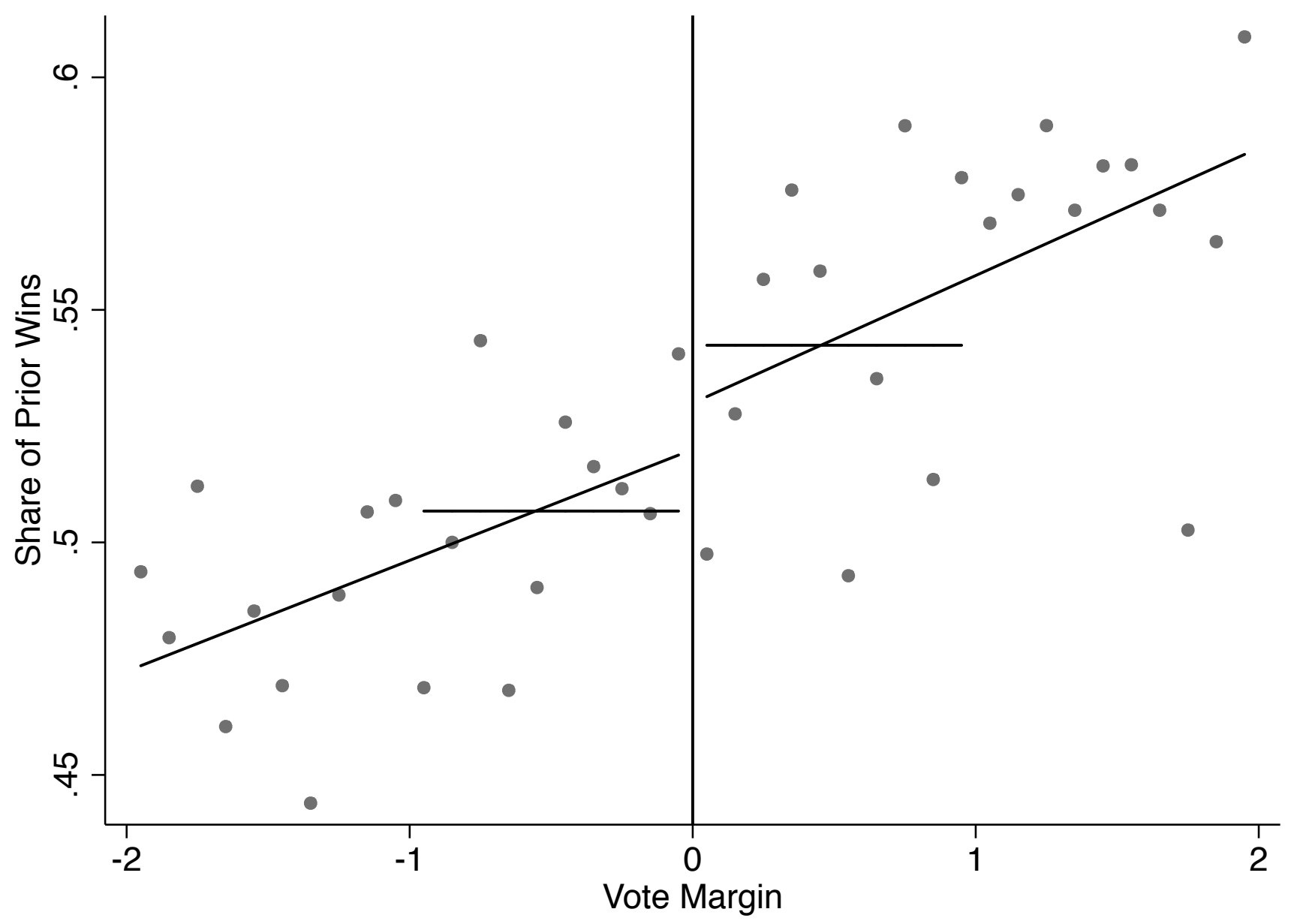


Figure B2: Testing for imbalances in lagged incumbent victory. We exclude bandwidths that subset the data to fewer than 60 observations.
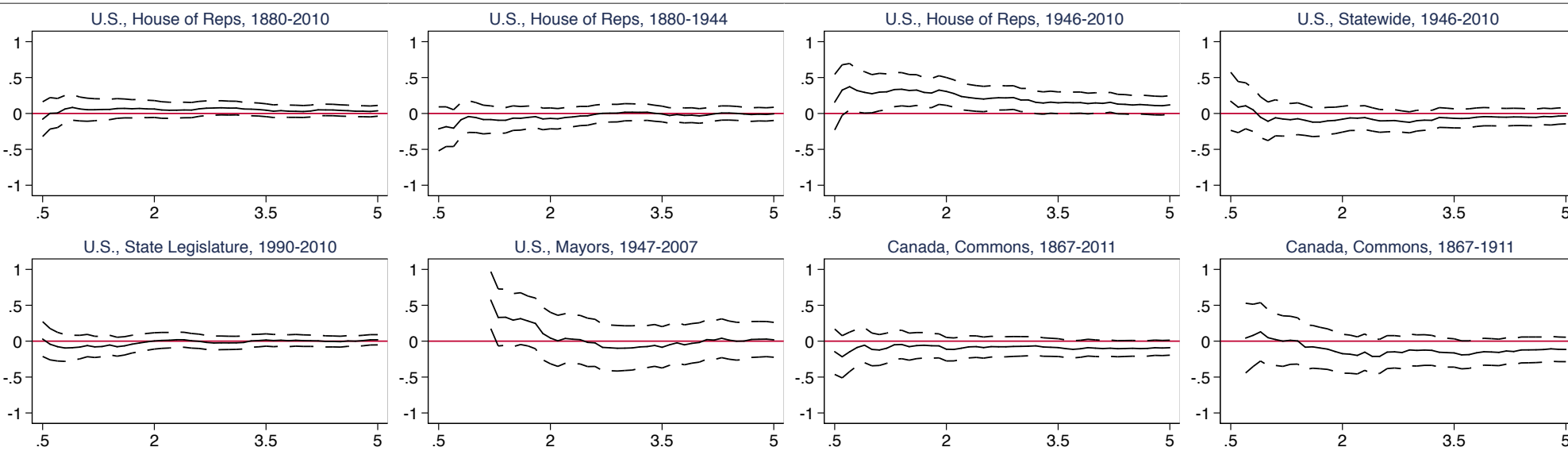

U.S., Mayors, $1947-2007$
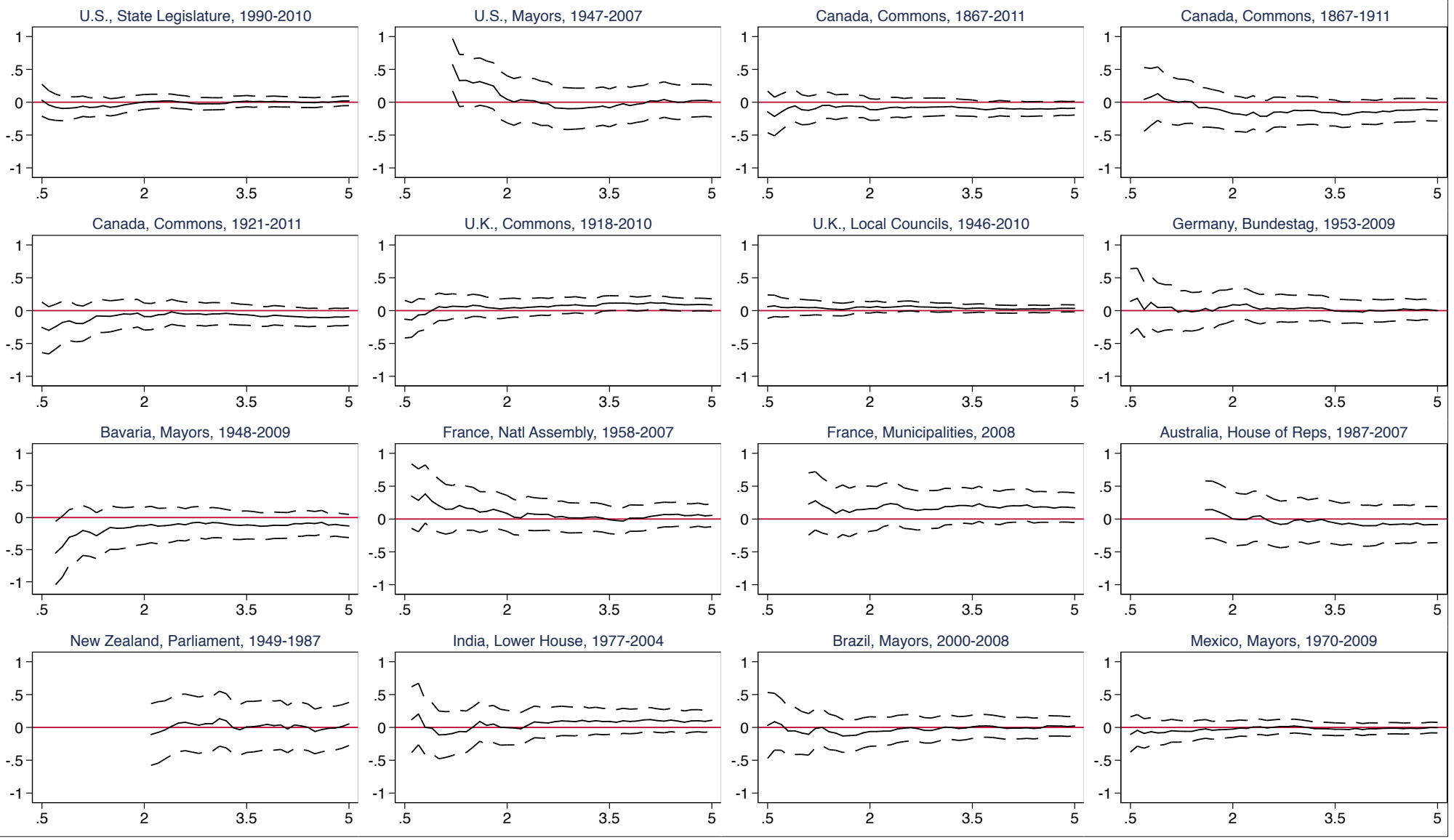
Figure B3: Testing for imbalances in lagged incumbent vote margin. We exclude bandwidths that subset the data to fewer than 60 observations.
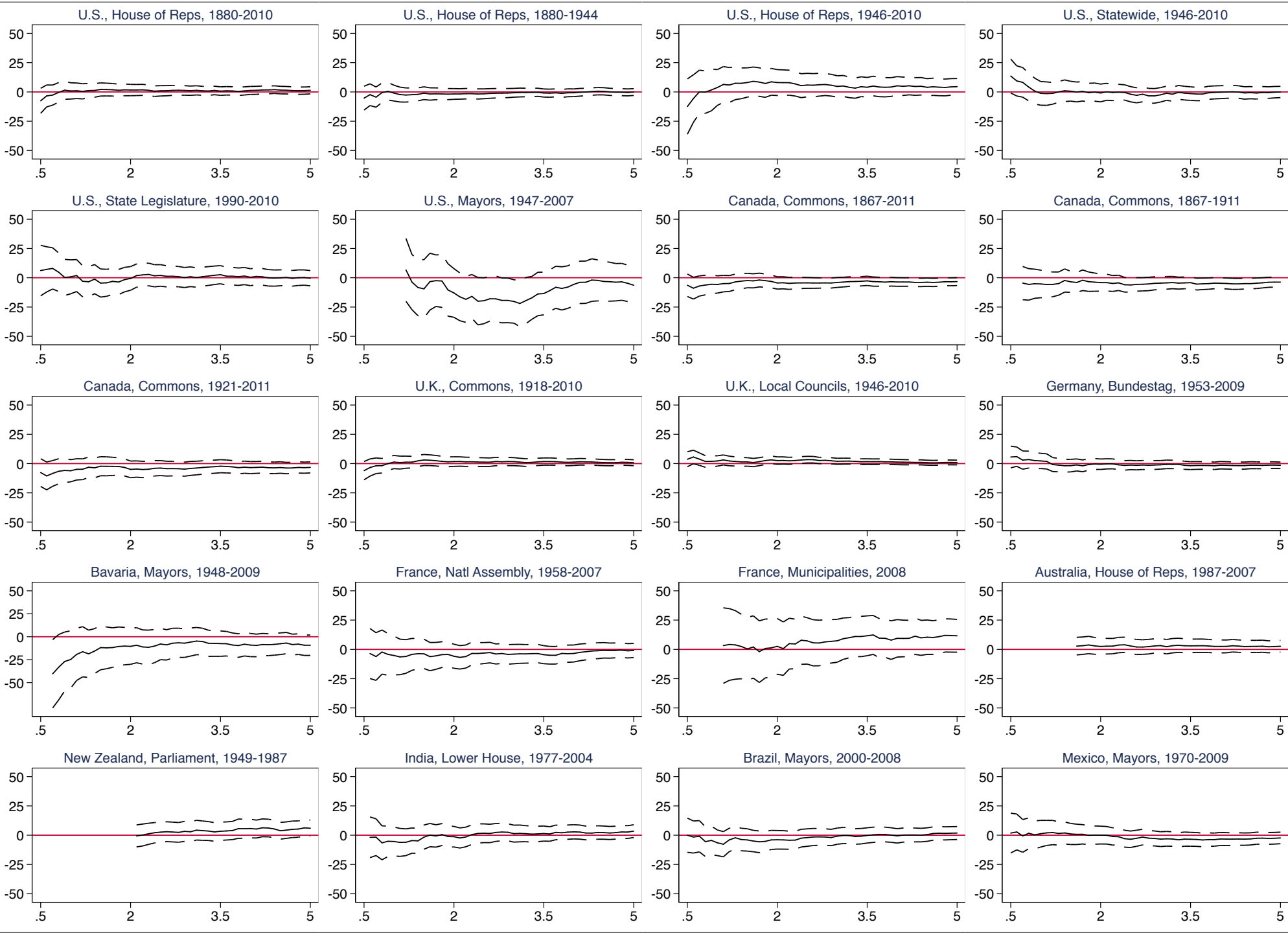
Figure B4: Testing for imbalances in lagged incumbent victory. All cases pooled.

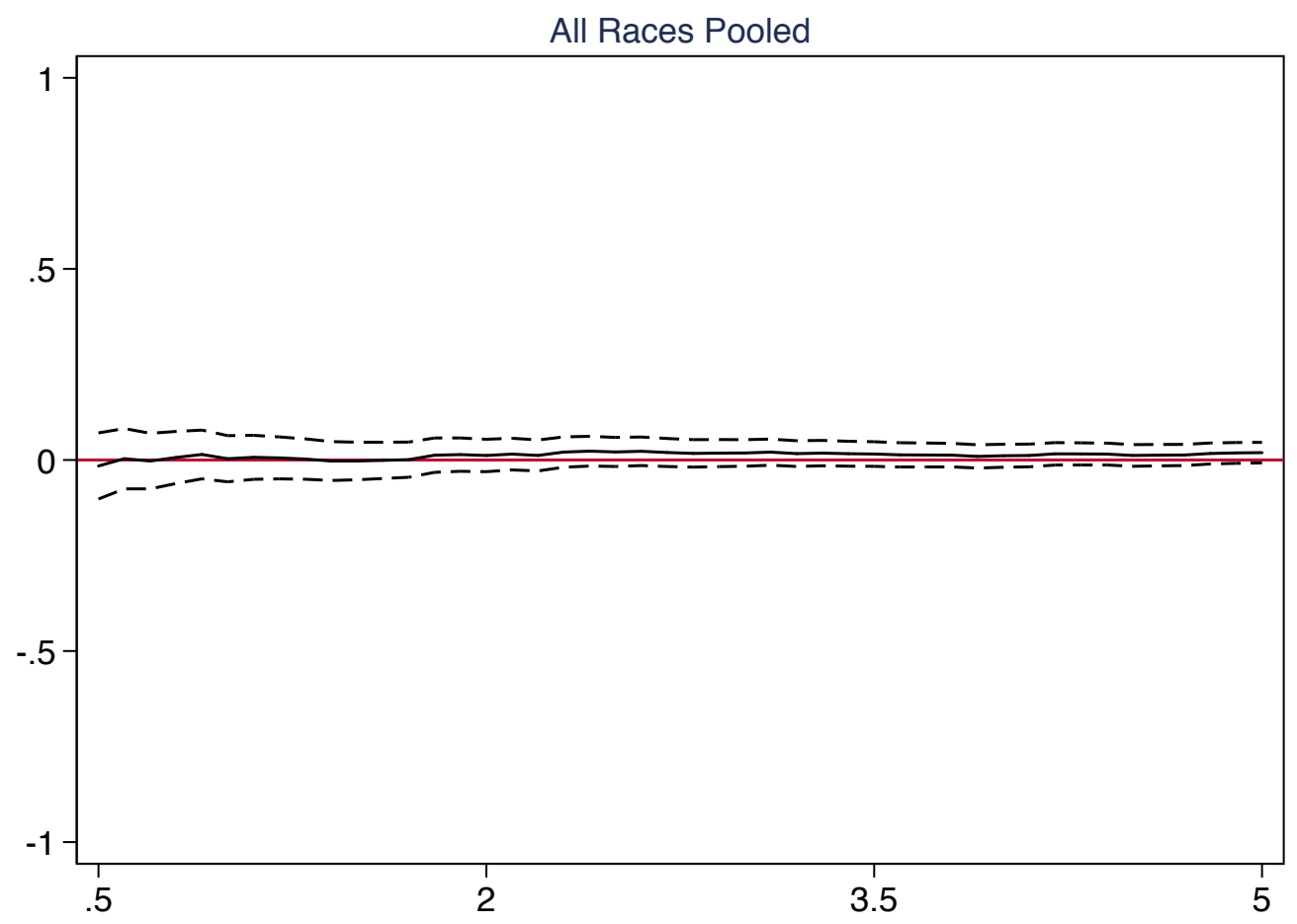


Figure B5: Testing for imbalances in lagged incumbent vote margin. All cases pooled.

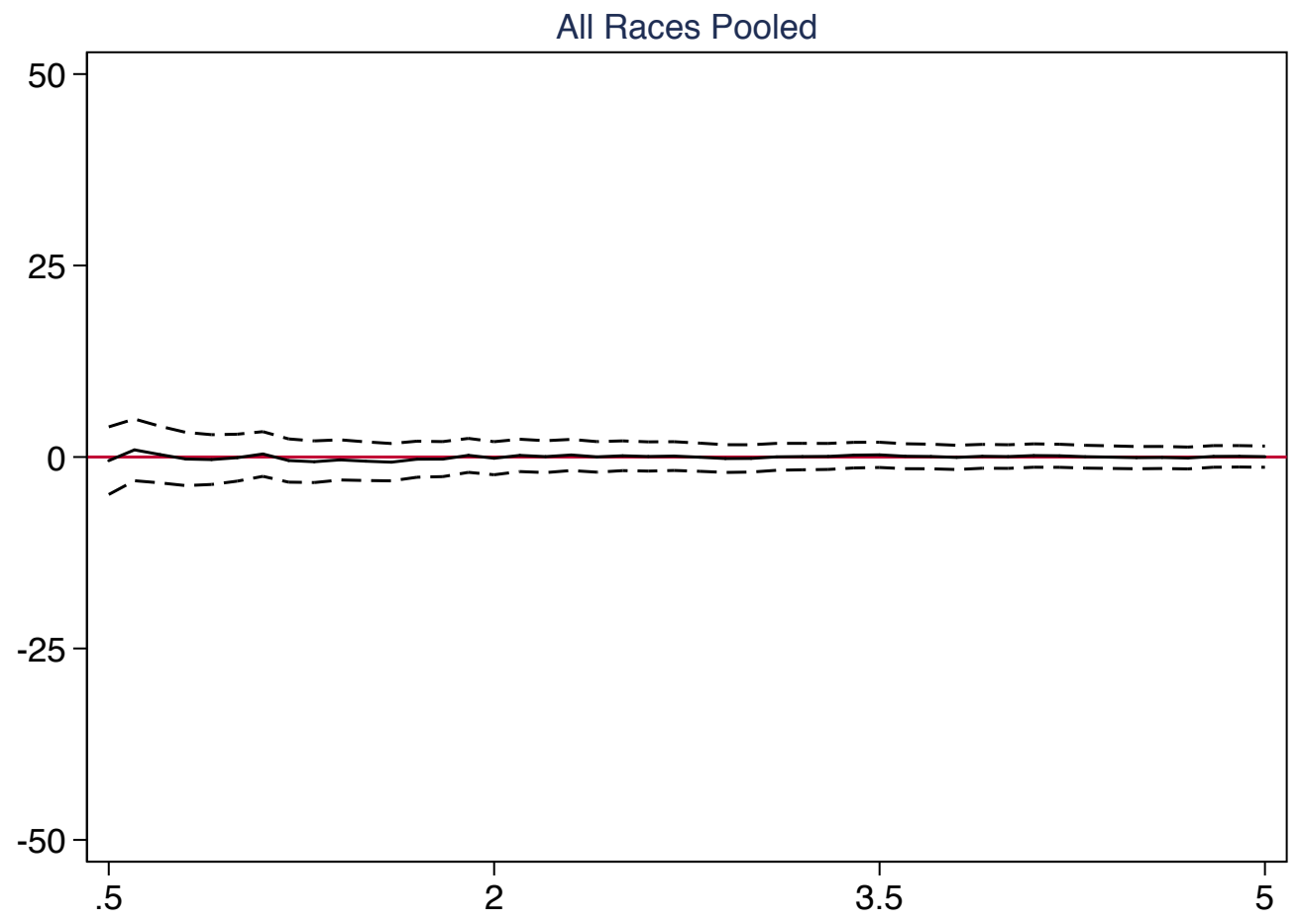




\section{Supporting Information Appendix C: Model of PRE-EleCtoral Manipulation}

How could pre-election behavior result in sorting of the kind discovered in the postwar U.S. House? Here, we adopt a theoretical model that captures the essence of the strategic campaigning hypothesis offered by Caughey and Sekhon or similar pre-election explanations. We use this model to assess the level of precision that relevant political actors would need to have in predicting election results in order for strategic pre-election behavior to explain the pattern of imbalances that we observe in the Post War U.S. House.

The model works as follows: incumbent candidates receive a signal about their expected vote share in the upcoming election - an indication of how they will perform if they proceed with a normal campaign. However, the signal is imperfect as there is some error in the candidate's prediction of the exact vote shares, and in the model, we assume that candidates are aware of the average level of error. This is analogous to the political polls that provide a signal to campaigns about the expected result and the known level of error associated with these polls, on average. After receiving the signal, incumbent candidates then decide whether to deploy a "secret weapon" - an extra campaign resource that will improve their vote share by a known amount. We could think of the secret weapon as extra effort, extra campaign resources, calling in favors, etc. Importantly, the deployment of this weapon is costly, so candidates will only use it if it will increase their probability of victory by a particular amount - whatever threshold at which the costs of deploying the weapon are equal, in expectation, to the benefits of such an increase in the probability of winning the election.

More formally, we can write the model as follows:

$$
\text { Inc Vote Share }=\text { signal }+ \text { error }+\kappa \cdot \text { secret weapon, }
$$

where signal $\sim N\left(.62, .15^{2}\right)$-approximating the distribution of incumbent vote share in the U.S. House, and error $\sim N\left(0, \epsilon^{2}\right)$. The variable $\kappa$ represents the effect of using the secret weapon on vote share, and secret weapon is a binary variable indicating whether the incumbent chooses to deploy the secret weapon. Our primary variable of interest is $\epsilon$ which indicates the average level of error in predicting vote shares. Specifically, we would like to find the largest possible value of $\epsilon$ that could produce the type of imbalance that we observe in the Post War U.S. House.

First, let us examine the decision of the incumbent to deploy the secret weapon. She must calculate her probability of victory if she deploys the weapon or abstains from doing so and then calculate the difference in these two probabilities. Specifically, the incumbent's probability of victory can be written in the following form:

$$
\begin{aligned}
\operatorname{Pr}(\text { signal }+ \text { error }+\kappa \cdot \text { secret weapon }>.5) & \\
& =\operatorname{Pr}(\text { error }>.5-\text { signal }-\kappa \cdot \text { secret weapon }) \\
& =\operatorname{Pr}(\text { error }<\kappa \cdot \text { secret weapon }+ \text { signal }-.5) \\
& =\Phi\left(\frac{\kappa \cdot \text { secret weapon }+ \text { signal }-.5}{\epsilon}\right)
\end{aligned}
$$

Therefore, the effect of deploying the secret weapon on the incumbent's probability of victory is 


$$
\Phi\left(\frac{\kappa+\text { signal }-.5}{\epsilon}\right)-\Phi\left(\frac{\text { signal }-.5}{\epsilon}\right)
$$

and the incumbent will only use this resource if

$$
\Phi\left(\frac{\kappa+\text { signal }-.5}{\epsilon}\right)-\Phi\left(\frac{\text { signal }-.5}{\epsilon}\right)>\alpha,
$$

where $\alpha$ represents the cost of deploying the secret weapon divided by the benefits of winning the election. Having evaluated the decision of the incumbent to employ the secret weapon, we can rewrite the distribution of incumbent vote share as

$$
\text { Inc Vote Share }=\text { signal }+ \text { error }+\kappa * 1\left\{\Phi\left(\frac{\kappa+\text { signal }-.5}{\epsilon}\right)-\Phi\left(\frac{\text { signal }-.5}{\epsilon}\right)>\alpha\right\},
$$

and evaluate how the distribution of incumbent vote share changes as a function of $\epsilon, \kappa$, and $\alpha$.

Our goal is to assess the possible values of $\epsilon$ that could potentially produce the type of imbalance observed in the U.S. House. As discussed in the main text, the imbalance observed in this setting is limited to the narrow sample of elections where the two-party vote percentage fell between 49.75 and 50.25 . Incumbents were more likely to fall in the small bin just above the winning threshold (between 50 and 50.25 percent) than they were to fall in the small bin just below the threshold (between 49.75 and 50 percent). In the sample analyzed by Caughey and Sekhon (2011), the incumbent party fell into the winning bin 75 times but only fell in the losing bin 35 times, so the incumbent party was approximately 2.14 times more likely to fall just above the winning threshold than just below. We use this ratio between the number of incumbent observations just above and just below the electoral threshold as our metric of imbalance, and determine the largest possible value of $\epsilon$ that could produce the same level of imbalance (2.14) that we observe in the U.S. House.

Assessing imbalance as a function of $\epsilon, \kappa$, and $\alpha$ is analytically difficult but can be easily accomplished through statistical simulations. For any given values of $\epsilon, \kappa$, and $\alpha$, we can generate one million observations resulting from this distribution of incumbent vote shares and estimate the level of imbalance produced by these specific values of these parameters. We repeat this procedure for approximately 2.5 million different possible combinations of parameters, ranging $\epsilon$ and $\kappa$ from .001 to .05 (0.01 to 5 percentage points) and ranging $\alpha$ from .01 to .99. Across all simulations, the largest possible value of $\epsilon$ that can produce the same level of imbalance in the U.S. House is .0026 or 0.26 percentage points. Within the model, in order for strategic pre-election behavior to produce the kind of imbalance observed in the U.S. House, incumbents or their campaigns would have to predict their expected vote shares at most within one-quarter of one percentage point, on average, and this is for only the best possible values of $\kappa$ and $\alpha$. This result confirms the intuition described in the main text. As we explain the main text, it seems implausible that real campaigns can obtain this level of precise knowledge about their expected vote shares, suggesting that strategic campaigning is not a convincing explanation of the imbalance that we observe in the U.S. House. STATA code for reproducing our simulation results is provided below.

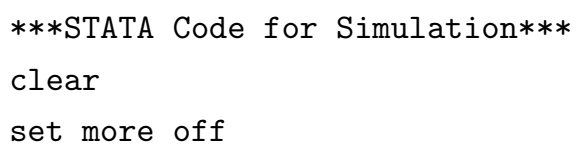




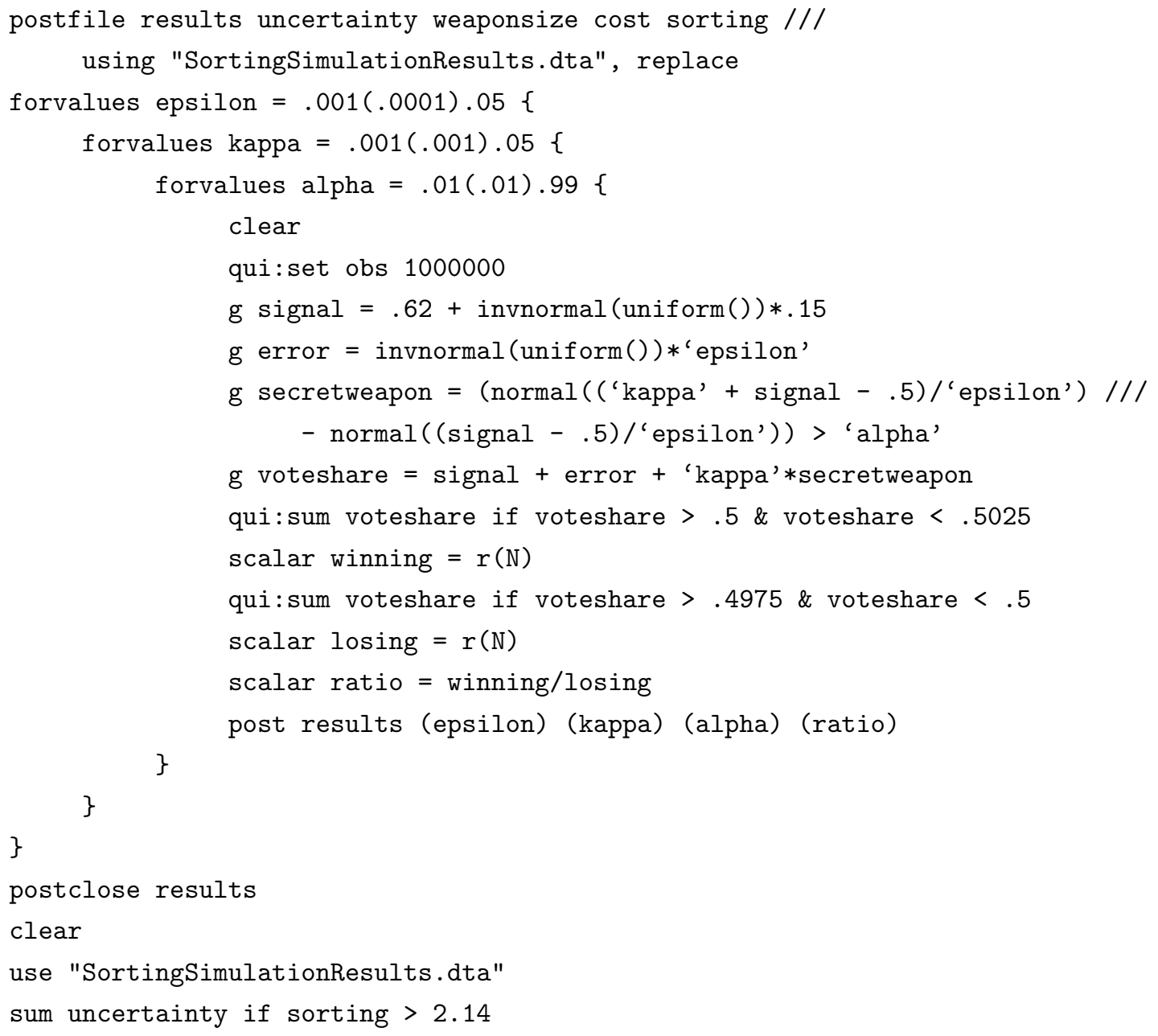

